\title{
Linking constructions in Mayrinax Atayal
}

Chunming Wu

Correspondence:

tomcm0606@163.com

School of Foreign Studies, Minnan

Normal University, Fujian, China

\begin{abstract}
This study investigated and examined linking constructions in Mayrinax Atayal. Although in the literature, linkers are categorized as either complementizers or aspectual heads, their syntactic behaviors and statuses have not been fully probed and analyzed. From minimalist and cartographic viewpoints, this paper will divide Mayrinax linking constructions into three classes with respect to their distribution, function, and representation. There is a complex selectional relationship among matrix predicates, linkers, and complements. The obligatory selectional restrictions imposed by matrix predicates determine the diverse structures of complements and the syntactic statuses or features of linkers. High-order evaluative verbs and factive cognition verbs c-select finite island complements headed by high linkers, which are weak finite complementizers that do not allow extractions. Utterance verbs, cognition verbs, and evidential/epistemic modals c-select normal finite complements headed by mid linkers, which are strong finite complementizers that allow extractions. Low-linking constructions are further divided into three categories. The deontic modal c-selects a non-finite AspP introduced by a type A low linker, which occupies the aspectual head position. Tough/middle evaluatives and object control verbs c-select a non-finite CP introduced by a type B low linker, which surfaces as a strong non-finite complementizer. Low adverbial verbs, subject control verbs, and resultative action verbs $C$-select a non-phase intransitive $V P$ introduced by a type $C$ low linker, which is realized as a vP-layer complementizer. The linker cartography is a reflection of the predicate hierarchy, which has been established and verified by a huge number of languages. The findings from this study will shed light on understanding phase theory and cartographic syntax in Formosan languages.
\end{abstract}

Keywords: Linkers; Cartographic; Minimalist; Selectional restriction; Weak/strong complementizer; Phase theory

\section{Introduction}

Linkers or ligatures, a category of functional words that connect a functional/lexical verb $^{\mathrm{a}}$ and its complement clause, are attested in certain Formosan languages such as Mayrinax Atayal, Paiwan, and Amis. These linker languages ${ }^{\mathrm{b}}$ may employ linkers in various multiple verb constructions to manifest syntactic relationships of complementation (Tsai and Wu 2012). Verbal categories such as adverbial, motion, posture, cognition, modal, and evaluation are associated with linking constructions.

Previous studies on Formosan linking constructions have focused mainly on complementation phenomena in individual languages. Linkers may have patterns with finite and non-finite complement clauses (Chen 2010; Tang 1999). There are mainly two types of analysis concerning the syntactic positions of linkers. First, linkers are not given specific

(c) The Author(s). 2017 Open Access This article is distributed under the terms of the Creative Commons Attribution 4.0 International License (http://creativecommons.org/licenses/by/4.0/), which permits unrestricted use, distribution, and reproduction in any medium, provided you give appropriate credit to the original author(s) and the source, provide a link to the Creative Commons license, and indicate if changes were made. 
syntactic status (Huang 1995). Second, linkers occupy head positions-they are either the complementizer heads (Liu 2011; Tang 1999) or the tense/aspect/modality (TAM ${ }^{\mathrm{C}}$ ) heads (Chen 2008, 2010). Although previous studies have achieved some descriptive/explanatory adequacy, the syntactic status of linkers remains controversial. "Non-specific status" analysis is inadequate in explaining the syntactic realization of linking constructions since canonical complementizers exist in Mayrinax Atayal according to Tang (1999) and Liu (2011). Complementizer analysis and aspectual head analysis may account for certain facets of linking constructions. These two analyses, however, encounter problems in other types of linking constructions. Mayrinax linkers are more extensively used than expected. Some linkers can occur in extremely high positions (above finite TP), as in (1a), while some occur in extremely low positions (below $\nu \mathrm{P}$ and $\mathrm{VP}$ ), as in $(1 \mathrm{~b}-\mathrm{c})$.

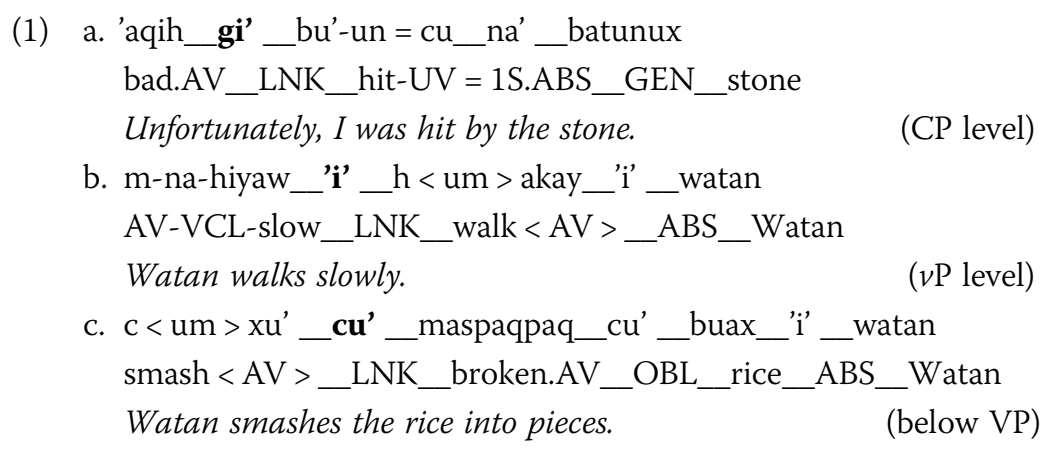

If linkers occur in syntactic contexts higher than finite TP, one question arises. Are these high-level linkers canonical complementizers? If not, what syntactic properties distinguish them from the canonical ones? Low-level linkers may give rise to another question. Since $\nu \mathrm{P}$ - and VP-level linkers exist in Mayrinax Atayal, it is inappropriate to analyze all of them as canonical complementizers if they can occur in a syntactic context lower than CP. Similarly, TAM head analysis is untenable because $\nu$ P-level linkers are unlikely to be TAM heads. If low-level linkers are not canonical $\mathrm{C}^{0}$ or $\mathrm{T}^{0}$ elements, which functional categories should they belong to? In addition to these status issues in structure, another major question remains. As illustrated in (1), Mayrinax linkers introduce complement clauses with different structures. What principles govern and determine the occurrences of the diverse structures in Mayrinax linking constructions? Is the structural diversity linkerdetermined or (matrix) predicate-determined?

This study examined various types of linking constructions in Mayrinax Atayal, which pervasively and obligatorily utilizes linkers in mono-clauses and complex clauses, with the aim to identify the syntactic positions of linkers, reveal syntactic mechanisms, and uncover the governing principles that determine the diverse structures in the linking constructions. The relevant structures that will be discussed are the $g i$,' $r u$, na, $m h a$, $g a$, $k i$,' $i$,' and $c u$ ' constructions. The results showed that linkers should be recategorized. Based on the minimalist program (Chomsky 2001) and a cartographic perspective (cf. Rizzi 1997; Tsai and Wu 2012), this paper will argue that Mayrinax linkers can be divided into three groups: high, mid, and low linkers. Each type of linker occupies a unique syntactic position in hierarchical structures. The linker statuses and properties are structure-determined, conditioned by the selectional restrictions determined by the 
matrix predicates and imposed on the complements. Such a linker hierarchy reflects a universal predicate hierarchy, which has been established in and verified by a huge number of languages (Cinque 1999).

This paper is organized as follows: Section 2 will introduce different types of linking constructions in Mayrinax Atayal, Section 3 will analyze the categorization of linkers and determine their syntactic statuses on the basis of c-selection and minimalist devices, Section 4 will discuss the different layers of matrix predicates and their selected linkers from a cartographic perspective, and Section 5 will present a concluding discussion.

\section{Linking constructions and verb types}

\subsection{Linking constructions in complementation}

Linking constructions are defined as constructions in which the first predicates and the embedded linker-marked phrases/clauses bear a complementation relationship rather than adjunction and conjunction. If two constituents are in complementation, some distinctive syntactic properties can be attested. Specifically, they usually occur in a rigid word order, as the movement and permutation of constituents are not allowed. This study excluded subordinate constructions in which an adjunct phrase/ clause can be moved in a sentence, such as ' $i$ ' makaxa' in (2a-b), as well as coordinate constructions in which permutation between the first conjunct and the second conjunct is allowed, as in (3a-b).

(2) a. pa-cbu'_cu'_bauwak_'i'_watan_'i' _maka-xa' IRR-shoot_OBL_pig_ABS_Watan_SUB_pass.through-two Watan will go hunting pigs two days after.

b. pa-cbu'_'i'_maka-xa'_cu'_bauwak_'i' _watan IRR-shoot_SUB_pass.through-two_OBL_pig_ABS_Watan Watan will go hunting pigs two days after.

(3) a. m-aquas_ru' _ $\mathrm{h}<\mathrm{um}>\mathrm{akay} \_$'i' _ watan AV-sing_CONJ_walk $<$ AV $>$ _ABS_Watan Watan is singing and walking.

b. $\mathrm{h}<\mathrm{um}>$ akay_ru' _m-aquas_'i' _watan walk $<\mathrm{AV}>$ _CONJ_AV-sing_ABS_Watan Watan is walking and singing.

Two additional diagnostics - an extraction test and a substitution test-are feasible in differentiating complementation from adjunction. First, it is possible to extract a DP from a complement clause, but not from an adjunct clause, owing to the island effect (Chang 2010). The DP bauwak base-generated within the complement clause in (4a) can be extracted as in (4b), but extracting a DP from an adjunct clause is not allowed, as in $(4 c-d)$.

(4) a. m-usa' _ ['i' _c $<$ um $>$ bu_cu' _bauwak] _'i' _watan AV-go_LNK_shoot $<$ AV $>$ _OBL_pig_ABS_Watan 
Watan went shooting pigs.

(Complementation)

b. 'usal-an_ni' _watan_ ['i' _c $<$ um $>$ bu' _ $\left.\boldsymbol{t}_{i}\right]$ _ ku' _ bauwak $_{i}$

go-LA_GEN_Watan_LNK_shoot $<\mathrm{AV}>$ _ ABS__pig

Watan went hunting the pig. (Complementation)

c. m-usa' _'i' _watan _i' _ papatasan_ ['i' _mumua' _cu' _bunga']

AV-go__ABS_Watan_LOC__school_SUB_plant.AV_OBL_sweet.potato

Watan went to school after planting sweet potatoes. (Adjunction)

d. *'usal-an_ni' watan_i' _papatasan_ ['i' _mumua' _ $t_{i}$ ] ku' _ bunga'

go-LA_GEN_Watan_LOC_school_SUB plant.AV_ABS sweet.potato

Intended: Watan went to school after planting sweet potatoes. (Adjunction)

Moreover, a complement clause together with its matrix clause is often treated as a unity that is strictly replaced by the verbal anaphora "do so" but this obligatory substitution is not attested in adjunction (see Metcalf 2005 for more discussion). The interpretation of the "do so" phrase in the second conjunct must include both the matrix clause and the complement clause in the first conjunct. Consider the following sentences in (5).

(5) a. m-usa'_['i'_c $<$ um $>$ bu'_cu'_bauwak]__i'_watan,__(ru')

_ giani__i'_yumin__uwi

AV-go_LNK shoot $<$ AV $>$

_OBL_pig_ABS_Watan__CONJ_do.so.AV_ABS_Yumin_too

Watan went to shoot pigs, and Yumin did so, too. (Complementation)

b. 'm-usa'_ ['i' _ c < um > bu' _ cu' _ bauwak] _ 'i' _watan,_(ru)

AV-go_LNK_shoot $\langle\mathrm{AV}\rangle$ _OBL__pig_ABS_Watan_CONJ_

giani_['i'_mutu'_cu'_kahuniq]_'i'_yumin_'uwi

do.so.AV_LNK_cut_OBL_wood_ABS_Yumin_too

Intended: Watan went to shoot pigs, and Yumin did so to cut woods,

too.

(Complementation)

In (5a), the interpretation of the verbal anaphora giani do so in the second conjunct must include both the matrix clause and the non-finite complement "went to shoot pigs". Giani do so cannot solely refer to the matrix verb musa' and exclude the reading of the complement clause. It is impossible to create the verbal event "to cut woods" as the complement in the second conjunct, as in (5b). This suggests that the structural affinity between the matrix clause and the complement clause is tight, and the verbal anaphora giani obligatorily covers both the matrix clause and the complement clause. By contrast, the interpretation of the do so phrase giani in the second conjunct does not necessarily include the adjunct in the first conjunct. The do so phrase can cover both the matrix clause and the adjunct clause, as in (6a), or can be anaphoric to the matrix verb/event solely (but exclude the interpretation of the adjunct ' $i$ ' maka- $x a$ ' in the first conjunct). Creating a new adjunct interpretation ' $i$ ' maka-tuu' in the second conjunct is plausible, as in (6b). The structural affinity between the matrix clause and the adjunct clause is lost, and the verbal anaphora giani does not obligatorily cover both the matrix clause and the adjunct clause. 
(6) a. m-a-'usa'_i'_bari_['i'_maka-xa']_'i'_watan

AV-IRR-go__LOC_Miaoli_SUB_be.through-two_ABS_Watan_

(ru')_pa-giani__i'_yumin

CONJ_IRR-do.so.AV__ABS_Yumin

Watan will go to Miaoli two days later and Yumin will do so, too.

b. m-a-'usa'_i'_bari_['i'_maka-xa']__i'_watan__

AV-IRR-go__LOC_Miaoli_SUB_be.through-two_ABS_Watan_

$(\mathrm{ru}$ ')_pa-giani__i'_yumin_'i'_maka-tuu'_'uwi

CONJ_IRR-do.so.AV_ABS_Yumin_SUB_be.through-three_too

Watan will go to Miaoli two days later and Yumin will do so three days later.

\subsection{Selection of verb/predicate types}

In the following sections, different types of complement-taking verbs/predicates will be selected for discussion. All of these complement-taking elements will be morphosyntactically divided into three categories: lexical verbs, adverbial verbs ${ }^{\mathrm{d}}$, and auxiliary verbs. Lexical verbs consist of high-order evaluatives, cognition verbs ${ }^{\mathrm{e}}$, utterance verbs, tough/middle predicates, control verbs, and causative dynamic verbs; adverbial verbs consist of manner and frequency expressions; and auxiliary verbs include evidential, deontic, and epistemic modals. All of these verbs may function as a predicate or occur as part of a predicate. In spite of their similarity, these verbs differ in some morphosyntactic behaviors. Lexical verbs are prototypical verbs that can be inflected for voice/ TAM, designate a subject in the non-actor voice (NAV) form, and attract clitics, as in (7a). Adverbial verbs are in the semi-lexical category, which may bear voice/TAM markers or attract clitics like lexical verbs but cannot freely designate a subject without the help of lexical verbs (Chang 2010), as in (7b). Unlike lexical verbs and adverbial verbs, which can be inflected for voice and TAM, auxiliary verbs are least verb-like but still retain a verbal property, such as clitic attraction (Huang 1995), as in (7c).

(7) a. la-lungulung-un $=m u \_k u$ '_ulaqi'

RED.IRR-think-UV = 1S.GEN__ABS_child

I will miss the child.

(Lexical verb)

b. 'a-'an-hi-hiyaw-un = mu_*('i'_l l<um > pug)_ku'_ruas

RED.IRR-VCL-RED-slow-UV $=1$ S.GEN_LNK_read $<$ AV $>$ _ABS_book

I will read the book slowly.

(Adverbial verb)

c. asi =cu_ki'_m-usa'_i'_bari

$\mathrm{DEON}=1 \mathrm{~S} . \mathrm{ABS} \_$LNK_AV-go_LOC_Miaoli

I must go to Miaoli.

(Auxiliary verb)

Mayrinax exhibits a rather complex selectional relationship among matrix verbs, linkers, and complement clauses with regard to finiteness. In this study, two criteria were used to differentiate finiteness from non-finiteness: clausal reducedness (i.e., a lack of an overt subject) and presence/absence of TAM marking. In short, evaluative verbs, cognition/utterance verbs, and epistemic/evidential modals select a full finite clause in which the subject is always present and the embedded verb can carry TAM markers. 
Control verbs, middle/tough predicates, adverbial verbs, and dynamic causative verbs select a reduced non-finite clause in which the subject is absent and the embedded verb does not bear any TAM marking.

\subsection{Finite complementation}

According to Huang (1995) and Liu (2011), Mayrinax finite clauses are introduced by six linkers. For example, the cognition verb snuawun "believe" selects a clause introduced by $c u_{\mathrm{F}}^{\prime}$ (F: finite), as in (8a); the utterance verb kumaal "tell" patterns with $m h a^{\prime}$ in (8b); the cognition verbs lumanglung "think" patterns with $r u$ ' in (8c), 'ua' "hope" with $n a$ ' in (8d), and ma'icug "afraid" with ' $i_{\mathrm{F} 2}^{\prime}$ in (8e); and the evidential asi "seem" patterns with $g a$ ' in (8f). The selection of these linker-introduced clauses is highly determined by the verb types. Readers may refer to Huang (1995) and Liu (2011) for more relevant data and discussions.

(8) a. snuaw-un =mu_cu'_m-a-'uah_'i'_casan_'i'_hiya' believe-UV $=1$ S.GEN_LNK_AV-IRR-come_FUT_tomorrow__ABS_3S

I believe that he will come tomorrow.

b. kal-un =mi'_hiya'_mha'_m-a-'usa'_i'_q $<$ um $>$ aluap_ tell-UV $=$ 1S.GEN.ABS_3S_LNK_AV-IRR-go_LLNK_hunt $\langle$ AV $>$ _ 'i'_casan_'i'_watan FUT_tomorrow_ABS_Watan

I told him that Watan will go hunting tomorrow.

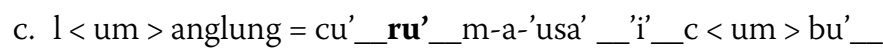
think $<$ AV $>=1$ S.ABS_LNK_AV-IRR-go_LLNK_shoot $<$ AV $>$ _ cu'_bauwak_'i'_casan_'i'_watan

OBL_pig_FUT_tomorrow_ABS_Watan

I am thinking that Watan will go hunting wild pigs tomorrow.

d. 'ua'_na'_m-a-'usa'_i'_mumua' hope.AV_LNK_AV-IRR-go_LNK_plant.AV cu'_raramat_i'_claq_'i'_casan_'i'_watan OBL_vegetables_LOC_field_FUT_tomorrow_ABS_Watan

I hope that Watan will go to plant vegetables tomorrow.

e. ma-'icug $=$ cu_'i'_ta-tuting-un $=\mathrm{cu}_{\text {_nni'_watan }}$ AV-afraid $=1$ S.ABS_LNK_RED.IRR-beat-UV $=1 S$. ABS_GEN_Watan I am afraid that Watan will beat me.

f. asi_ga'_iqaat_m $<$ in $>$ tauwaw_cuhisa'_'i'_watan seem_LNK_NEG__work $<$ PERF $>$.AV_yesterday_ABS_ Watan It seems that Watan didn't work yesterday.

This section will additionally illustrate high-level linking constructions that are less discussed in the literature, such as those in (9a-d).

(9) a. balaiq_gi'_ini' $=$ cu_bu'-i_na'_batunux good.AV_LNK_NEG = 1S.ABS_hit-UV.IMP_GEN_stone

Fortunately, I was not hit by the stone.

b. nahriq_'i'_pa-pakati'_ni'_watan_ku'_mami' 


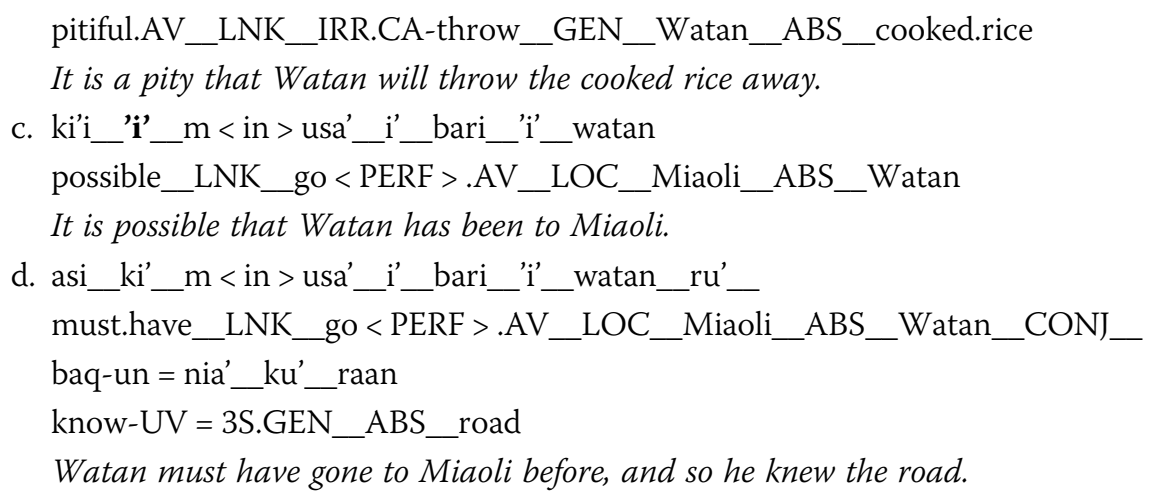

The evaluative verb balaiq "good" may select complement clauses introduced by the linker gi, as in (9a), and the high-order evaluative nahriq (Tsai and Wu 2012) may select a finite clause headed by the linker ' ${ }^{\prime}$ ' 1 , as in (9b). These two constructions are used to convey the speaker's evaluative attitude and judgment of an event. In (9c), the epistemic modal ki $i$ selects a clause headed by the linker ' $i$ ' 2 , which is homophonous to the previous linker in (9b). In (9d), the epistemic modal $a s i^{\mathrm{f}}$ selects a clause introduced by the linker $k i_{\mathrm{F}}$ (cf. Yu 2015). The ' $i{ }_{\mathrm{F} 2}$-marked and $k i_{\mathrm{F}}$-marked constructions express an epistemic/hypothetical reading in this case.

The complement clauses introduced by linkers in $(9 a-d)$ are definitely finite. The embedded verbs freely bear irrealis/perfective marking, as in (9b-d), and they may also be freely inflected for the actor voice (AV) and the NAV. In contrast to embedded verbs, matrix/first verbs are morphosyntactically restricted and defective. In linking constructions, the evaluative verbs balaiq and nahriq obligatorily surface as bare AV verbs by default. In (10a-b), balaiq and nahriq are prohibited from taking the irrealis marker $p a$ - or the perfective marker $<i n>$. In addition, it cannot attract pronominal clitics, such as $=c u /=s u$ '.

(10) a. "pa-k-balaiq $\left({ }^{*}=\mathrm{cu}\right)$ _gi'_ini' $=\mathrm{cubu}$-i__na'_stone IRR-STA-Good.AV(=1S.ABS)_LNK_NEG = 1S.ABS_hitUV.NIND_GEN_batunux

b. " $\mathrm{m}<\mathrm{in}>\mathrm{a}$-nahriq $\left.{ }^{(*}=\mathrm{su}^{\prime}\right) \_$'i'_si-pakati' $=\mathrm{su}^{\prime} \_\mathrm{ku}$ '_mami' AV $<$ PERF $>-$ pitiful $(=2 S . G E N) \_$LNK_CA-pitiful= 2S.GEN_ABS_cooked.rice

It is noteworthy that evaluative verbs like balaiq and nahriq can serve as lexical verbs on their own, as they can stand independently and designate a nominal argument in a clause, and they can be inflected for TAM and the NAV and may attract pronominal clitics, as in (11a-b).

(11) a. ka-k-blaiq-un = nia'_ku'_'imuag RED.IRR-STA-good-UV = 3S.GEN_ABS_house He will fix up the house.

b. ka-nahriq-un $=$ mu_ku'_qulih STA-pitiful-UV $=1$ S.GEN_ABS_fish 


\section{I felt pity for the fish.}

Interestingly, when evaluative verbs occur in linking constructions, they are morphosyntactically uninfected for TAM and obligatorily realized in bare AV forms by default. In these constructions, the evaluative verbs denote a generic judgment, viewpoint, or attitude of a speaker. These verbs occur as default stative verbs to express a generic state of personal judgment or attitude ${ }^{\mathrm{g}}$. In this case, any TAM/NAV inflection on these stative verbs is redundant in its evaluative reading.

The modal ki'i behaves like an auxiliary verb and is thus unmarked for TAM or voice marking. It can only attract clitic pronouns, such as $=s u^{\prime}$ in (12).

(12) $\mathrm{ki}^{\prime} \mathrm{i}=\mathrm{si}^{\prime} \_\mathrm{m}<\mathrm{in}>$ usa'_i'_bari

possible $=2$ S.ABS.LNK_go $<$ PERF $>$ _LOC_Miaoli

It is possible that you have been to Miaoli.

\subsection{Non-finite complementation}

Non-finite complements are reduced clauses that lack an overt subject; the embedded verbs are not inflected for TAM. In the literature (Tang 1999), an AV-only restriction is often treated as a non-finite restriction that is imposed on the complement clause. However, this study revealed that some reduced complement clauses, which were not characterized by an AV-only restriction, were still non-finite, with the embedded verbs unable to take any TAM markers. In this sense, an AV-only restriction is not the only indication of non-finiteness in Mayrinax Atayal.

\subsubsection{Constructions with an AV-only restriction}

An AV-only restriction on non-finite complementation, which will be discussed later, is well documented in the literature on Formosan languages (Chang 2006; Huang 1997; Tang 1999). In Mayrinax Atayal, there are four non-finite constructions in which the complements are subject to the AV-only restriction: low adverbial verb constructions, subject control constructions, object control constructions, and resultative constructions. The first three types of constructions, which are associated with the linker ' $i_{\mathrm{NF}}$ (NF, non-finite), have been widely reported and discussed (Chang 2009, 2010; Huang 1995; Huang 1997). However, the resultative construction, which is associated with the linker $\mathrm{cu}_{\mathrm{NF}}^{\prime}$, has been ignored in previous studies.

\subsubsection{AV-only ' $i{ }_{\mathrm{NF}}$ construction}

Non-finite AV-only ' $i$ ' ${ }_{N F}$ constructions can be further divided into three types. The first type involves low adverbial verb constructions. In low adverbial verb constructions, the first verb is always an adverbial verb, such as manner and frequency adverbials, and the second verb is a lexical verb. Mayrinax low adverbial verb constructions exhibit properties of both Siraya types and Paiwan types (cf. Chang 2010). The adverbial verbs in (13) entertain lexical prefixes that exert a verb-classifying function, and the occurrence of the AV-only linker ' $i$ '

(13) a. mti-hiya-hiyaw_'i'_maniq_cu'_mami'_i'_tali' 


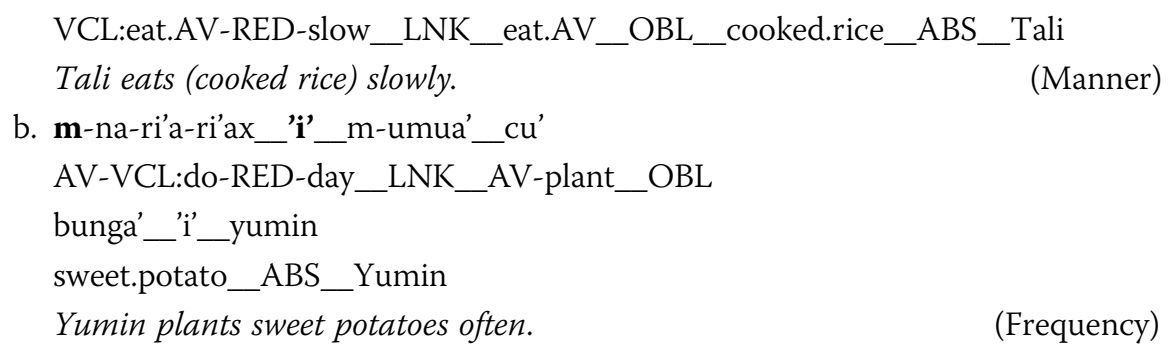

The second type concerns the subject control construction (the serial verb construction in Huang's (1997) definition). This construction is associated with various verb types, including posture verbs, aspectual verbs, motion verbs, attempt verbs, and dynamic modal verbs ${ }^{\mathrm{h}}$. Some examples are illustrated in (14).

(14) a. m-ancaqrug__i'_[maniq__u'_mami'PRO $\left.{ }_{i}\right]_{\text {__ 'i'_watan }}$ $\mathrm{AV}$-stand_LNK_eat.AV__OBL_cooked.rice__ABS_Watan

Watan ate cooked rice while standing.

(Posture)

b. baq__i'_ $[1<\mathrm{um}>\text { anguyPRO } i]_{\ldots}$ 'i'_watan ${ }_{i}$ be.able.to.AV_LNK__swim $<\mathrm{AV}>$ _ ABS_Watan

Watan is able to swim./Lit. Watan knows how to swim. $\quad$ (Dynamic modal)

In this construction, the first verb and the second verb are both lexical verbs. The actor of the matrix clause is a shared thematic "subject" that serves as the controller for PRO in the embedded clause, such as $\operatorname{watan}_{i}$ in (14a-b).

The third type is the object control construction (namely, the pivotal construction in Huang's (1995) definition; see also Chang and Tsai (2001)). Like the subject control construction, the two verbs in the object control ${ }^{\mathrm{i}}$ construction are lexical. The shared argument is the thematic "object" (limuy in (15)) selected by the manipulative verb. The shared object is therefore the controller for the embedded clause.

(15) siwal-an_ni_yumin__i'_limuy ${ }_{j}\left[\right.$ ['i'_maniq_cku'_qulih $\left.\mathrm{PRO}_{j}\right]$

allow-LA_GEN_Yumin_ABS_Limuy_LNK_eat.AV_OBL_fish

Yumin allowed Limuy to eat fish.

Although the AV-only ' $i$ ' ${ }_{\mathrm{NF}}$ construction discussed above accommodates various verb types, they have one property in common, and the structure of complementation is asymmetrical. Each type of construction respects the AV-only restriction, with the first verbs bearing major morphosyntactic marking, while the second verbs are defective in morphosyntactic marking and occur as bare AV forms. The examples below show that only the first verbs can bear either the perfective marker, as in (16a, 16b, and 16c), or the irrealis marker, as in (16a, 16b', and 16c'), but the second verb cannot.

(16) a. $\mathrm{m}<$ in $>$-ti-hiya-hiyaw_i'_maniq/* $\mathbf{m}<$ in $>$ aniq__cu'_mami'_

AV $<$ PERF $>$-eat-RED-slow_LNK_eat.AV/*eat $<$

$\mathrm{PERF}>. \mathrm{AV} \_\mathrm{OBL} \_$cooked.rice__

'i'_tali' 
ABS_Tali

Tali ate (cooked rice) slowly.

(Adverbial verb construction)

a'. pa-pti-hiya-hiyaw_'i'_maniq/"pa-qaniq_cu'_mami'

IRR.AV-eat-RED-slow_LNK_eat.AV/"IRR.AV-eat_OBL_cooked.rice_

'i'_tali'

ABS_Tali

Tali will eat (cooked rice) slowly.

(Adverbial verb construction)

b. m- $<$ in $>$ usa'_'i'_q $<$ um $>$ aluap/"q $<$ um $><$ in $>$ aluap_

AV- $<$ PERF $>$ go_LNK_hunt $<\mathrm{AV}>/$ "hunt $<\mathrm{AV}><\mathrm{PERF}>$ _

cu'_bauwak_'i'_watan

OBL_pig_LNK_Watan

Watan went hunting pig.

(Subject control construction)

b'. m-a-'usa'_i'_q < um > aluap/"pa-qaluap__

AV-IRR-go_LNK_hunt $<$ AV $>$ /"IRR-hunt_

cu'_bauwak_'i'_watan

OBL_pig_LNK_Watan

Watan will go hunting pig.

c. $s<$ in $>$ iwal-an_ni_yumin_'i'_limuy

allow $<$ PERF $>$-LA_GEN_Yumin_ABS_Limuy

'i'_maniq/"*m $<$ in $>$ aniq_cku'_qulih

LNK_eat.AV/"eat $<\mathrm{PERF}>$.AV_OBL_fish

Yumin allowed Limuy to eat fish.

(Object control construction)

c'. sa-siwal-an_ni_yumin_'i'_limuy

RED.IRR-allow-LA_GEN_Yumin_ABS_Limuy

'i'_maniq/"pa-qaniq_cku'_qulih

LNK_eat.AV/"IRR-eat.AV_OBL_fish

Yumin will allow Limuy to eat fish.

(Subject control construction)

In addition, the matrix verb can be freely inflected for the NAV, such as the undergoer voice (UV) in (17a) or the circumstantial applicative $e^{j}(\mathrm{CA})$ in (17b) and the locative applicative (LA) in (17c), but not the second verb.

(17) a. pa-pti-hi-hiyaw-un=mi'_'i'_maniq/*niq-un__ku'_qulih

RED-eat-RED-slow-UV = 1S.GEN_LLN_eat.AV/eat-UV__ABS_fish

I will eat the fish slowly. (Adverbial verb construction)

b. si-qabaq_'i'_c $<$ um > bu'/*si-cbu'_ni'_watan_cu'_bauwak_

CA-be.able.to_LNK_shoot $<$ AV $>/ C A$-shoot_GEN_Watan_OBL_pig__

ku'_patus

ABS_gun

Watan is able to hunt pigs with the gun. (Subject control construction)

c. siwal-an_ni_yumin_'i'_limuy_'i'_maniq/"niq-an_cku'_qulih

allow-LA_GEN_Yumin_ABS_Limuy_LNK_eat.AV/"eat-LA_OBL_fish

Yumin allowed Limuy to eat fish.

(Object control construction) 
This structural asymmetry can also be evidenced by the fact that only first verbs can attract pronominal clitics, but not second verbs. An overt actor or subject does not occur in the AV-only ' $i$ ' ${ }_{N F}$ complement. In $(18 \mathrm{a}-\mathrm{c})$, the pronominal clitics $=c u /=m u$ cannot be attached to the embedded verbs.

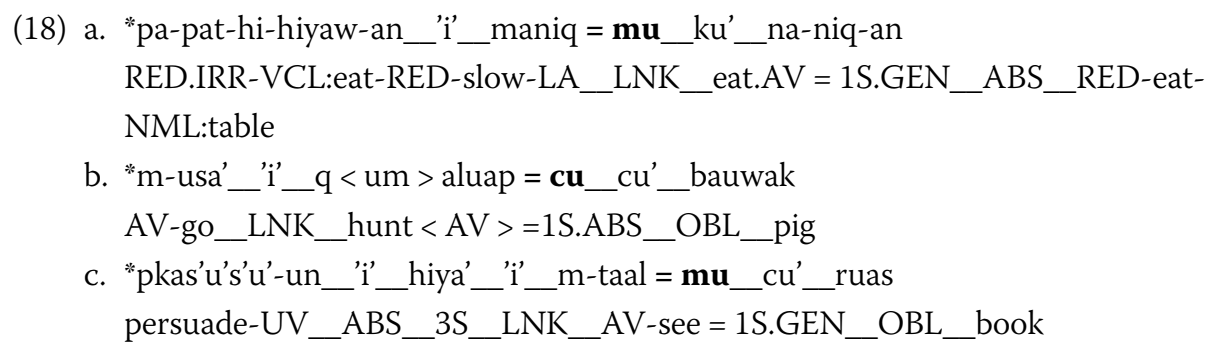

\subsubsection{2 $\mathrm{cu}_{\mathrm{NF}}^{\prime}$ construction}

According to Huang (1995) and Liu (2011), the linker $c u_{\mathrm{F}}^{\prime}$ introduces finite clauses in Mayrinax. In addition, Mayrinax has another homophonous linker- $c u_{\mathrm{NF}}^{\prime}-$ to introduce a nonfinite clause in the resultative construction. The second predicates headed by $\mathrm{cu}^{\prime}{ }_{\mathrm{NF}}$ convey resultative events, while the first verbs convey causative events. The resultative events are often realized by stative verbs and the causative events by dynamic verbs, as in (19a-b). The resultative construction here must observe a rigid word order: the causative verb must precede the resultative verb, and permutation between stative and causative verbs is not allowed, as in $\left(19 a-b^{k}\right)$.

(19) a. c $<$ um $>$ xu'_cu'_maspaqpaq_cu'_buax_'i'_watan smash $<\mathrm{AV}\rangle$ _LNK_broken.AV_OBL_rice_ABS_Watan

Watan smashes the rice into pieces.

b. 'maspaqpaq_cu'_c $<$ um $>$ xu'_cu'_buax_'i'_watan broken.AV_LNK_smash $\langle$ AV $>$ _OBL_rice_ABS_Watan

There is also an AV-only restriction on $\mathrm{cu}^{\prime}{ }_{\mathrm{NF}}$ complementation. The first verb freely carries TAM or voice markers, whereas the embedded verb disallows any TAM/NAV marking. The embedded verb must remain non-finite in its AV form. The NAVinflected embedded verbs in (20) and the TAM-inflected embedded verbs in (21) may give rise to ungrammatical results.

(20) a. 'uquq-un_cu'_ma-huwiq/"pa-k-huwiq-un_ni'_watan_ku'_situing soak-UV_LNK_AV-wet/CAUS-STA-wet-

UV_GEN_Watan_ABS_clothes

Watan soaked the clothes wet.

b. p-nubuw-an_cu'_mabusuk/"pa-k-busuk-an_ni'_watan CAUS-drink-LA_LNK_drunk.AV/CAUS-STA-drunk-LA_GEN_Watan_ 'i'_hiya' 
Watan made him drunk.

c. si-caum_cu'_matanah/"si-pa-ka-tanah_cu'_qiniriang_

CA-paint_LNK_red.AV/*CA-CAUS-STA-red-UV_OBL_wall_

ni'_watan_'i'_tapas

GEN_Watan_ABS_Tapas

Watan painted the wall red for Tapas.

(21) a. ' $<$ um $><$ in $>$ aquuq_cu'_ma-huwiq/*m $<$ in $>$

a-huwiq_cu'_situing__'i'_watan

soak $<$ AV $><$ PERF $>$ _LNK_AV-wet $/ \mathrm{AV}<\mathrm{PERF}>$

-wet_OBL_clothes_ABS_Watan

Watan soaked the clothes wet.

b. 'a-'uquq-un_cu'_ma-huwiq/"pa-ka-huwiq_ni'_watan_ku'_situing

RED.IRR-soak-UV_LNK_AV-wet/IRR-STA-wet-

UV_GEN_Watan_ABS_clothes

Watan soaked the clothes wet.

The complement clause usually shares the same subject with the matrix clause. In $(22 \mathrm{a}-\mathrm{b})$, the pronominal clitics $=c u /=m u$ are obligatorily attached to the matrix predicates. An overt actor or subject is not allowed in the complement clause.

(22) a. ' $<$ um $><$ in $>$ aquuq $=$ cu_cu'_ma-huwiq( $\left.{ }^{*}=\mathrm{cu}\right) \_c u$ '_situing

soak $<\mathrm{AV}><\mathrm{PERF}>=1 \mathrm{~S}$.ABSLNKAV-wet(=1S.ABS)_OBL_clothes

I soaked clothes wet.

b. 'a-'uquq-un $=$ mu_cu'_ma-huwiq(* $\left.{ }^{*}=m u\right) \_k u$ '_situing

RED.IRR-soak-UV $=1 S . G E N \_L N K \_A V-w e t(=1 S . G E N)$ _ABS_clothes

I soaked the clothes wet.

\subsubsection{Constructions without an AV-only restriction}

\subsubsection{Non-AV-only ' $i$ '}

In contrast to the AV-only ' $i$ ' dle/tough predicates are not subject to the AV-only restriction ${ }^{1}$. In these cases, the constraint is imposed on TAM rather than voice. Example (23) shows sentences characterized by the non-AV-only ' $i_{\mathrm{NF}}$ complements. These sentences express readings equivalent to English middle/tough constructions.

(23) a. mkaruux_'i'_mingilis_ku'_'ulaqi'_ka'_hani.

easy.AV_LNK_cry.AV_ABS_child_NL_this

This child is easy to cry.

b. balaiq_'i'_patbins-un_ku'_raramat_ka'_hani.

good.AV_LNK_sell-UV_ABS_vegetables_NL_this

These vegetables sell well./Lit. These vegetables are good to sell.

c. 'ayhung__i'_patas-an_ku'_ruas_ka'_hani.

hard.AV_LNK_read-LA_ABS_book_NL_this

This book is hard to read. 
d. 'aqih_'i'_si-caqis_cu'_situing_ku'_ragum_ka'_hani. bad.AV_LNK_CA-sew_OBL_clothes_ABS_needle_NL_this

This needle is hard to use to sew the clothes.

The embedded verbs remain tenseless ${ }^{\mathrm{m}}$, albeit in their voice-inflected forms, namely, AV in (23a), UV in (23b), LA in (23c), and CA in (23d). The irrealis marking and the perfective marking cannot occur in the complement clause, as in (24a-b).

(24) a. "'aihung__i'_pa-patas-an_ku'_ruas_ka'_hani. hard.AV_LNK_RED.IRR-read-LA_ABS_book_NL_this

b. 'aqih_'i'_c $<$ in $>$ aqis_cu'_situing_ku'_ragum_ka'_hani. bad.AV_LNK_sew $<$ PERF.CA $>$ _ OBL__clothes_ABS_needle_NL_this

The examples in (25a) and (25b) show that it is always the first verb that carries the TAM marking. Note that the first verb is by default an AV stative verb and cannot be realized in its NAV form ${ }^{\mathrm{n}}$. The AV stative verb can attract pronominal nominative and genitive clitics, as in (25c).

(25) a. pa-k-'aihung_'i'_lapg-un_ku'_ruas_ka'_hani IRR-STA-hard.AV_LNK_read-UV__ABS_book_NL_this

This book will be hard to read.

b. $\mathrm{m}<\mathrm{in}>\mathrm{a}$-'aqih__i'_si-caqis_cu'_situing_ku'_ragum_ka'_hani. $\mathrm{AV}<\mathrm{PERF}>-\mathrm{bad} \_\mathrm{LNK} \_\mathrm{CA}$-sew_OBL_clothes_ABS_needle_NL_this This needle was hard to use to sew the clothes.

c. 'ayhung = mi'_patas-an__ku'_ruas__ka'_hani hard.AV = 1S.GEN.LNK_read-LA_ABS_book_NL_this

This book is hard for me to read.

\subsubsection{2 $k i_{\mathrm{NF}}$ construction}

The modal $a s i_{\text {deon }}$ may select a complement clause introduced by the linker $k i$ ' ${ }_{\mathrm{NF}}$. The whole proposition conveys a deontic reading. Morphosyntactically, the deontic asi $i_{\text {deon }}$ is unmarked for TAM or voice. However, it may attract clitic pronouns, as in (26b).

(26) a. asi_ki'_matiq = su

DEON_LNK_write.AV = 2S.ABS

You must study.

b. asi = su_ki'_matiq

$\mathrm{DEON}=2 \mathrm{~S} . \mathrm{ABS} \_$LNK_ _ write.AV

You must study.

The embedded verb of the $k i$ ' ${ }_{\text {NF }}$ complement can be freely inflected for AV (26a), UV (27a), CA (27b), and LA (27c) but must remain non-finite.

(27) a. asi_ki'_pumua'-un $=\mathrm{mu} /{ }^{* *} \mathrm{p}<$ in $>$ umua' $=\mathrm{mu} /{ }^{*}$ pa-pumua' - un $=\mathrm{mu}$ DEON_LNK__plant-UV $=1$ S.GEN/plant $<$ PERF.UV $>=1 S . G E N / R E D . I R R-$ plant-UV 
ku'_bunga'

ABS_sweet.potatoes

I must plant the sweet potatoes.

b. asi_ki'_si-cbu' $=\mathrm{mu} /{ }^{*} \mathrm{c}<\mathrm{in}>\mathrm{bu}^{\prime}=\mathrm{mu} /{ }^{*} \mathrm{ca}-\mathrm{cbu}{ }^{\prime}=\mathrm{mu}$

DEON LNK CA-shoot $=1$ S.GEN/shoot $<$ PERF.CA $>=1$ S.GEN/RED.IRR.CA-

shoot = 1S.GENcu'_bauwak_'i'_hiya'

$\mathrm{OBL} \_$_pig_ABS_3S

I must shoot pigs for him.

c. asi_ki__tal-an $=$ mi' $^{\prime *} \mathrm{k}<$ in $>$ tal-an $=$ mi' $/{ }^{*}$ ta-tal-an $=$ mi'_hiya'

DEON_LNK

see-LA = 1S.GEN.ABS $/$ see $<$ PERF $>-L A=1 S . G E N . A B S / R E D . I R R-$ see-LA =

1S.GEN.ABS_3S.ABS

I must see her.

\subsection{Summary}

Table 1 incorporates the findings of Huang (1995) and Liu (2011) and summarizes different verb/predicate types and their selection of linkers in Mayrinax Atayal. It has been found that the selection of linkers is divergent and complicated. In finite complementation, there are one-to-many and one-to-one relationships in the selectional restrictions between the matrix verbs/predicates and the complement clauses headed by linkers (cf. Huang 1995; Liu 2011). On the one hand, a verb/predicate may select different types of linkers. For example, the cognition verb lumanglung "to think" may select ru' and mha, and baqun "to know" may select $r u^{\prime}$ and $c u$ '. On the other hand, a strong one-to-one restriction is obligatory. For example, the high-order evaluative balaiq selects gi' while nahriq selects ' $i_{\mathrm{F} 1}$. These two

Table 1 Verb/predicate types and the selection of linkers in Mayrinax Atayal (I)

\begin{tabular}{|c|c|c|c|c|c|c|c|c|c|}
\hline $\begin{array}{l}\text { Linkers } \\
\text { Verb/predicate types }\end{array}$ & & $g i^{\prime}$ & $r u^{\prime}$ & $n a^{\prime}$ & $m h a^{\prime}$ & $g a^{\prime}$ & $\begin{array}{l}k i_{F}^{\prime} \\
k i_{N F}^{\prime}\end{array}$ & $\begin{array}{l}i_{F 1}^{\prime} \\
i_{F 2}^{\prime} \\
i^{\prime}{ }_{N F}\end{array}$ & $\begin{array}{l}c U_{F}^{\prime} \\
c U_{N F}^{\prime}\end{array}$ \\
\hline High-order evaluative & balaiq "good/fortunate" & $\checkmark$ & & & & & & & \\
\hline & nahriq "pitiful"' & & & & & & & $\boldsymbol{\checkmark}^{\prime \prime} i_{F 1}^{\prime}$ & \\
\hline Cognition verb & snuawun "to believe" & & & & & & & & $\checkmark C U_{F}^{\prime}$ \\
\hline & lumanglung "to think" & & $\checkmark$ & & $\checkmark$ & & & & \\
\hline & baqun "to know" & & $\checkmark$ & & & & & & $\checkmark c u_{F}^{\prime}$ \\
\hline & 'ua' "to hope" & & & $\checkmark$ & & & & & \\
\hline & ma'icug "to be afraid" & & & & & & & $\boldsymbol{J}^{\prime \prime} i_{F 2}^{\prime}$ & \\
\hline $\begin{array}{l}\text { Utterance } \\
\text { verb }\end{array}$ & kumaal "to say" & & & & $\checkmark$ & & & & \\
\hline Evidential & asi $_{\text {evid }}$ & & & & & $\checkmark$ & & & \\
\hline Epistemic & $k i i$ & & & & & & & $\boldsymbol{J}^{\prime \prime} i_{F 2}^{\prime}$ & \\
\hline & $a_{\text {esis }}$ & & & & & & $\checkmark k i_{F}^{\prime}$ & & \\
\hline Deontic & asideon & & & & & & $\checkmark k i_{N F}^{\prime}$ & & \\
\hline Middle/tough predicate & & & & & & & & $\checkmark^{\prime \prime} i_{\mathrm{NF}}$ & \\
\hline Subject control verb & & & & & & & & $\boldsymbol{J}^{\prime \prime}{ }_{\mathrm{NF}}^{\prime}$ & \\
\hline Object control verb & & & & & & & & $\boldsymbol{J}^{\prime \prime}{ }_{\mathrm{NF}}^{\prime}$ & \\
\hline Adverbial verb (manne & (frequency) & & & & & & & $\boldsymbol{J}^{\prime \prime}{ }_{\mathrm{NF}}^{\prime}$ & \\
\hline Action verb in resultati & e construction & & & & & & & & $\checkmark C U_{N F}^{\prime}$ \\
\hline
\end{tabular}


predicates are in the same semantic category. In other cases, the cognition verb ' $u a$ ' selects the linker na', ma'icug the linker ' $i$ ' ${ }_{\mathrm{F} 2}$, an utterance verb the linker $m h a$, the evidential modal $a s i_{\text {evid }}$ the linker $g a$, the epistemic modal ki'i the linker ' $i$ ' ${ }_{\mathrm{F} 2}$, and the epistemic modal $a s i_{\text {epis }}$ the linker $k i_{\mathrm{F}}$. In non-finite complementation, however, the selection of linkers is rather predictable. The deontic modal $a s i_{\text {deon }}$ selects $k i_{\mathrm{NF}}$; the tough/middle evaluative, the subject and object control verbs, and low adverbial verbs select ' $i_{\mathrm{NF}}$; and resultative action verbs select $c u_{\mathrm{NF}}^{\prime}$. The following sections will recategorize the matrix predicates and their selected linkers according to differences in syntactic functions and behaviors.

\section{Syntactic realizations of Mayrinax linkers}

\subsection{Previous analysis}

Liu (2011) has claimed that most of the Mayrinax linkers should be analyzed as complementizers based on two pieces of evidence: (1) these linkers behave differently from other functional categories such as conjunctions, subordinators, and case markers; and (2) as complementizers, these linkers occupy the $\mathrm{C}^{0}$ position, are able to host a wh-argument in its SPEC position, and do not block wh-extraction ${ }^{\circ}$, such as the linker $c u_{\mathrm{F}}^{\prime}$ in $(28 \mathrm{a}-\mathrm{b})$.

(28) Mayrinax Atayal (Liu 2011:134)

a. baq-un_ni'_yata'_cu'_[nanuan ${ }_{i}\left[\mathrm{ku}^{\prime} \_\right.$na-niq-un_ know-UV_GEN_aunt_LNK_what_ABS_RED.IRR-eat-UV_

nku'_ulaqi' $\left.t_{i}\right]$ ]

GEN_child

Lit. Does the aunt know what the child will eat?

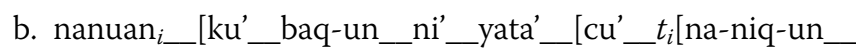

what_ABS_know-UV_GEN_aunt_LNK_RED.IRR-eat-UV_

nku'_'ulaqi' $\left.\left.t_{i}\right]\right]$ ]

GEN_child

Lit. Does the aunt know what the child will eat?

In addition, Liu (2011) also pointed out that Mayrinax has a hybrid linker $r u$, which bears the properties of both a conjunction and a complementizer and blocks wh-extraction.

(29) Mayrinax Atayal (Liu 2011: 141)

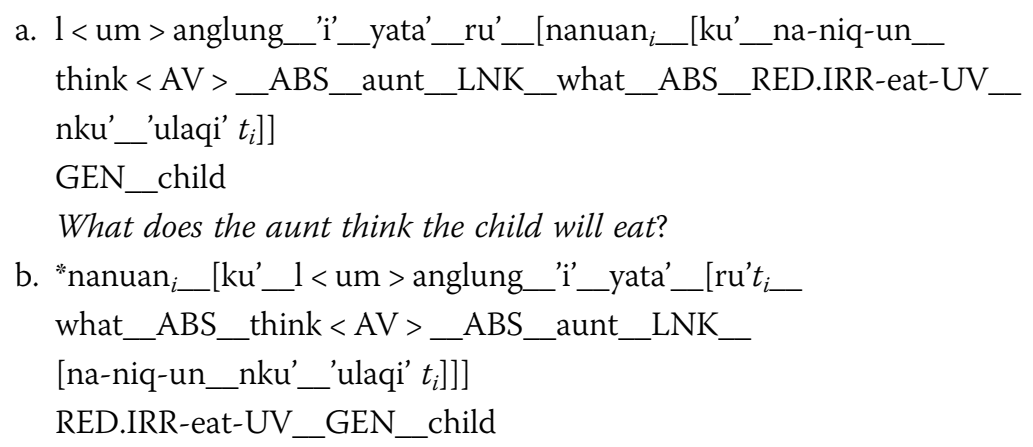

Liu's (2011) study showed that Mayrinax linkers are divided into two types: (1) a hybrid category (both a complementizer and a coordinator) that blocks wh-extraction; and (2) a finite complementizer that does not. The blocking effect can be attributed to 
the hybrid property of the linker. However, Liu's (2011) analysis cannot account for the contrast shown in (30) and (31).

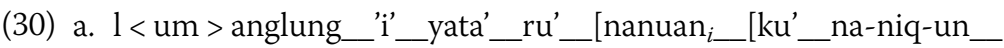

think $\langle\mathrm{AV}\rangle$ _ABS_aunt_LNK_what_ABS_RED.IRR-eat-UV_

nku'_'ulaqi' $t_{i}$ ]

GEN_child

What does the aunt think the child will eat?

b. "nanuan ${ }_{i \_}\left[\mathrm{ku}_{\text {___ }} \mathrm{l}<\mathrm{um}>\right.$ anglung__i'_yata'_[ru' $t_{i}$ what_ABS_think $<\mathrm{AV}>$ _ABS_aunt_LNK_

[na-niq-un_nku'_'ulaqi't $t_{i}$ ]]]

RED.IRR-eat-UV_GEN_child

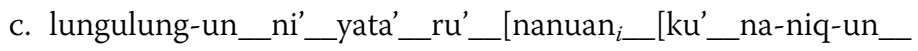

think-UV_GEN_aunt_LNK_what_ABS_RED.IRR-eat-UV_

nku'_'ulaqi't $\left.\left.t_{i}\right]\right]$

GEN_child

What does the aunt think the child will eat?

d. 'nanuan ${ }_{i}\left[\right.$ [ku'_lungulung-un_ni'_yata'_[ru't $t_{i}$ what_ABS_think-UV_GEN_aunt_LNK_

[na-niq-un_nku'_'ulaqi't $\left.t_{i}\right]$ ]

RED.IRR-eat-UV_GEN_child

(31) a. s < um $>$ nauwaw__i'_yata'_cu'_[nanuan ${ }_{i} \_\left[k^{\prime} u^{\prime} \_ \text {na-niq-un }\right.$

believe $\langle$ AV $>$ _ABS_aunt_LNK_what_ABS_RED.IRR-eat-UV_

nku'_'ulaqi't $\left.\left.t_{i}\right]\right]$

GEN_child

What does the aunt believe that the child will eat?

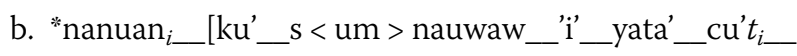

what_ABS_believe $<\mathrm{AV}>$ _ABS_aunt_LNK_

[na-niq-un_nku'_'ulaqi't $t_{i}$ ]]

RED.IRR-eat-UV_GEN_child

c. snuaw-un_ni'_yata'_cu'_[nanuan ${ }_{i \_}\left[\mathrm{ku}{ }^{\prime} \_\right.$na-niq-un

believe-UV_GEN_aunt_LNK_what_ABS_RED.IRR-eat-UV_

nku'_'ulaqi't $\left.\left.t_{i}\right]\right]$

GEN_child

What does the aunt believe that the child will eat?

d. nanuan ${ }_{i}$ [ku'_snuaw-un_ni'_yata'_cu' $t_{i}$

what_ABS_believe-UV_GEN_aunt_LNK_

[na-niq-un_nku'_'ulaqi't $t_{i}$ ]

RED.IRR-eat-UV_GEN_child

What does the aunt believe that the child will eat?

In (30b) and (30d), by no means does the wh-argument undergo extraction from the $r u^{\prime}$ clause, no matter whether the matrix verb "think" is realized in the AV or NAV form. In Liu's (2011) analysis, the $r u$ ' clause may form a conjunct island where extracting elements is prohibited (Huang 1982); however, that analysis did not predict why the blocking effect 
took place with the non-blocking complementizer. According to Liu (2011), $\mathrm{cu}_{\mathrm{F}}^{\prime}$ is a finite complementizer that does not block wh-extraction. As shown by the contrast in (31b) and (31d), the wh-argument successfully undergoes extraction from the embedded $c u^{\prime}{ }_{F}$ clause when the matrix verb is inflected for the NAV, but the extraction fails when the matrix verb surfaces as its AV form. In addition to the island condition, are there other factors that can affect the blocking effect taking place in the non-blocking categories?

\subsection{A minimalist analysis based on the C-selection approach}

This study will provide new observations by adopting a c-selection-based featurevaluation approach to account for extraction distinction in finite complementation. The following sections will show that (1) Mayrinax has two other linking constructions that block wh-extractions, and (2) the blocking effect is not only attested in wh-extraction but also can extend to topic extraction and clitic climbing. As will be argued, the blocking effect can either be c-selection-driven or phase/locality-determined. In addition, Liu's (2011) study focused on linkers involved in finite complementation. However, Mayrinax has linkers that are homophonous with finite linkers but introduce non-finite complements (e.g., $k i_{\mathrm{NF}}{ }^{\prime}{ }_{\mathrm{NF}}$, and $c u_{\mathrm{NF}}$ ). This phenomenon leaves finite complementizer analysis unaccounted for. These non-finite linkers can be insensitive to diagnostics for finite complementation, so their syntactic statuses should be reconsidered.

\subsubsection{A brief introduction to minimalist analysis}

In the operation of the minimalist program (MP), agreement is considered a by-product of case assignment. Once a Probe (functional head) with non-interpretable features is merged into syntax, it must immediately check off its uninterpretable features [uF] with a Goal (DP argument). This probe-goal agreement must respect the locality principle: the searching domain of the Probe-Goal must be minimal. In this sense, the Goal is always the closest candidate as the Probe searches downward, as shown in Fig. 1.

According to Chomsky (2001), C, T, and $v$ heads are legitimate Probes for structure case assignment. Phrasal movement is no longer triggered by agreement, but instead by the presence of an EPP feature. The phrasal element or the Goal that agrees with the Probe moves into the specifier position if the EPP feature occurs on the head, as shown in Fig. 2. This EPP-driven movement must be performed under the Phase Impenetrability Condition (PIC): only the edge of a phase $(\nu \mathrm{P}, \mathrm{CP})$ is accessible to operations (Chomsky 2001: 5).

This MP operation varies from language to language. Aldridge (2004) has proposed that ergative languages should be distinguished from accusative ones with regard to differences in their feature-valuation patterns, as shown by the three-way distinction in Table 2.

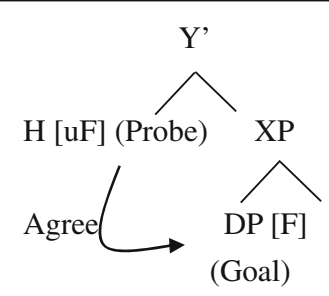

Fig. 1 Probe-Goal agreement 


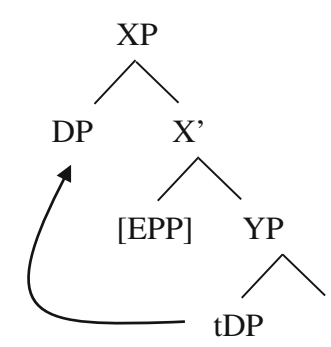

Fig. 2 Movement driven by EPP

Accusative languages like English usually have a nominative case feature and an EPP feature on T. The EPP feature triggers the subject to move to the specifier position of the TP. The transitive $v$ bears the accusative case feature and an optional EPP feature. The optional EPP feature is responsible for the movement of the internal argument (i.e., wh-extraction). Ergative languages have two types of operating systems. In a $v$-type ergative language like Tagalog, there is a division of labor between $\mathrm{T}$ and $v$ with respect to absolutive case-checking. The transitive $v$ bearing the inherent ergative case checks the absolutive case for the internal argument. In intransitive clauses, however, the absolutive case is supplied by $\mathrm{T}$, which does not carry an EPP feature. Formosan languages (including Mayrinax Atayal) belong to T-type ergative languages, where $\mathrm{T}$ is responsible for absolutive case-checking in both transitive and intransitive clauses, while transitive $v$ supplies only the EPP feature.

According to Aldridge (2004), this two-way distinction hinges on the difference in absolutive case assignment in the control construction. In Tagalog control construction, the non-finite verb can surface as an NAV verb and a subject DP can occur within the non-finite complement, as in (32).

(32) Tagalog (Aldridge 2008: 1448)

Nagba-balak_ang_babae-ng_[PRO tulung-an_ang_lalaki]

INTR.PROG-plan_ABS_woman-LK_help-APP_ABS_man

The woman is planning to help the man.

In (32), there are two DP arguments that are marked as ABS. The question is, how can the two DPs both be assigned ABS case features? It is frequently assumed that the absolutive case should be equated with the nominative case and therefore should be valued by $T$. In (32), only the matrix $T$ assigns the ABS case feature, which targets

Table 2 Feature valuation and language variation

\begin{tabular}{|c|c|c|c|}
\hline \multirow{2}{*}{$\begin{array}{l}\text { Language } \\
\text { Functional head }\end{array}$} & \multirow[t]{2}{*}{ Accusative language } & \multicolumn{2}{|l|}{ Ergative language } \\
\hline & & $v$ type & T type \\
\hline Transitive $v$ & $\begin{array}{l}\text { [UCASE:OBL] } \\
\text { Optional [EPP] }\end{array}$ & $\begin{array}{l}\text { Inherent ergative case } \\
\text { [uCASE:ABS] } \\
\text { [EPP] }\end{array}$ & $\begin{array}{l}\text { Inherent ergative case } \\
\text { [EPP] }\end{array}$ \\
\hline Intransitive $v$ & $\begin{array}{l}\text { No case feature } \\
\text { No [EPP] feature }\end{array}$ & $\begin{array}{l}\text { No case feature } \\
\text { No [EPP] feature }\end{array}$ & $\begin{array}{l}\text { No case feature } \\
\text { No [EPP] feature }\end{array}$ \\
\hline Finite $T$ & $\begin{array}{l}\text { [UCASE: ABS] } \\
\text { [EPP] }\end{array}$ & Optional [UCASE: ABS] & $\begin{array}{l}\text { [UCASE: ABS] } \\
\text { No [EPP] }\end{array}$ \\
\hline
\end{tabular}


its closest DP babae, since the matrix $v$ is intransitive and carries no case feature. But how does the embedded DP receive ABS since in the non-finite embedded clause, a defective $T$ cannot assign an ABS case feature? In this sense, it is obvious that the source of the absolutive case in embedded clauses must be transitive $v$ and cannot be matrix T. That is why Tagalog is called a $v$-type ergative language. In contrast, Mayrinax Atayal is grouped as a T-type ergative language because Mayrinax does not have the Tagalog-type control construction in which the embedded verb is transitive (NAV). In Mayrinax Atayal the control construction cannot accommodate two ABSmarked DPs, and the embedded verb is subject to AV-only restriction and cannot occur as a transitive (NAV) form, as shown in (33b).

(33) Mayrinax Atayal

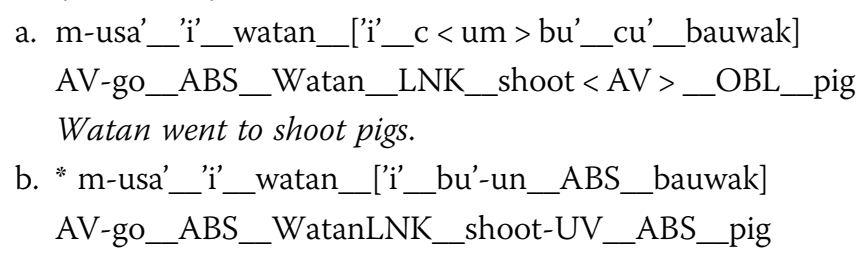

It should be the matrix $\mathrm{T}$ that is responsible for $\mathrm{ABS}$ feature assignment since there is only one subject in the Mayrinax control construction, as in (33a). The following sections will adopt $\mathrm{T}$-type ergative analysis to tackle these problems.

\subsubsection{High linkers selected as weak complementizers}

Liu (2011) has indicated that most Mayrinax linkers are true complementizers that introduce finite clauses and allow the wh-argument to be extracted from the embedded clause. However, the linker ru' is an exception. Consider the following examples in (34): the linker ru'can introduce a fully inflected clause (finite TP), a pseudo-cleft clause, and a topic clause as its complements.

(34) a. $1<\mathrm{um}>$ anglung $=\mathrm{cu} \_r u$ _ $\mathrm{m}<\mathrm{in}>\mathrm{uah} \_\mathrm{i} \_$runi_'i'_watan_cuhisa'

think $<\mathrm{AV}>=1 \mathrm{~S}$.ABS_LNK__come $<$ PERF $>. A V \_L O C \_$here_ABS_Watan_yesterday

I thought that Watan came here yesterday.

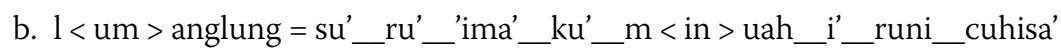

think $<\mathrm{AV}>=2 \mathrm{~S}$.ABS_LNK__who_ABS_come $<$

PERF $>$.AV_LOC_here_yesterday

Who did you think came here yesterday?

c. $1<$ um $>$ anglung = su'_ru'_watan_ga'_m $<$ in $>$ uah__i__runi_cuhisa'

think $<\mathrm{AV}>=2 \mathrm{~S} . \mathrm{ABS} \_$LNK__Watan_TOP_come $<$

PERF $>. A V \_L O C \_$here_yesterday

You thought that Watan is the one who came here yesterday.

As demonstrated by (35b), the wh-argument 'ima' cannot be extracted from the $r u$ 'marked clause. According to Liu (2011), ru' bears the properties of both a conjunction and a complementizer. The extraction therefore violates Ross's (1967) CSC, in which the coordinating structure does not allow extraction out of a conjunct. 


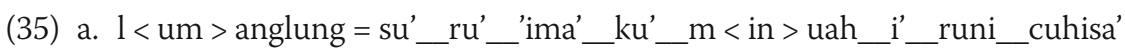

think $<\mathrm{AV}>=2 \mathrm{~S}$.ABS_LNK__who__ABS_come $<$

PERF $>$.AV_LOC_ here_yesterday

Who did you think came here yesterday?

b. "'ima'_ku'_l $<\mathrm{um}>$ anglung $=\mathrm{su}^{\prime} \_$ru'_m $<\mathrm{in}>\mathrm{uah} \_\mathrm{i}$ '_runi_cuhisa'

who__ABS_think $<\mathrm{AV}>=2 \mathrm{~S}$.ABS_LNK__come $<$

PERF $>. \mathrm{AV}_{\text {_LCOC_here_yesterday }}$

One may assume that if the first verb shifts to its NAV form, the extraction will be workable. However, this assumption cannot be borne out. In (36b), the subject DPs still fail to undergo extraction when the first verbs occur in NAV forms.

(36) a. lungulung-un = su'_ru'_'ima'_ku'_m $<$ in $>$ uah_i'_runi_cuhisa'

think-UV $=2$ S.GEN_LNK_who__ABS__come $<$

PERF > .AV_LOC__here_yesterday

Who did you think came here yesterday?

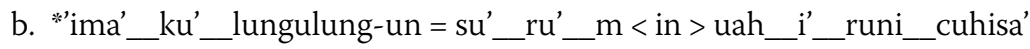

who__ABS_think-UV $=2 S . G E N \_L N K \_$come $<$

PERF > .AV_LOC_here_yesterday

A similar blocking effect may be carried over to topic extraction. The topics of the embedded clauses cannot undergo further extraction. As shown in (37b) and (37d), the extraction of topics from the embedded clauses is disallowed, regardless of whether the first cognition verb is an AV or an NAV.

(37) a. l<um $>$ anglung = su'_ru'_watan_ga'_m- $<$ in $>$ uah_i'_runi_cuhisa' think $<\mathrm{AV}>=2 \mathrm{~S}$.ABS_LNK_Watan__TOP_AV-come $<$ PERF $>$ _LOC_here_yesterday You thought that Watan is the one who came here yesterday.

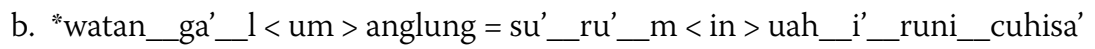
Watan_TOP_think $<$ AV $>=2 S$.ABS_LNK_AV-come $<$ PERF $>$ _LOC_here_yesterday

c. lungulung-un $=m u \_r u$ _ $\_$watan_ ga'_ $m<$ in $>$ uah_i'_runi_cuhisa' think-UV = 1S.GEN_LNK_Watan_TOP_come $<$ PERF > .AV_LOC_here_yesterday Watan is the one I thought of came here yesterday?

d. 'watan_ga'_lungulung-un $=m u \_r u$ __ $\mathrm{m}<\mathrm{in}>\mathrm{uah} \_\mathrm{i}$ __runi_cuhisa' Watan_TOP_think-UV $=1$ S.GEN_LNK_come $<$ PERF > .AV_LOC_here_yesterday

In addition to the ru' construction reported by Liu (2011), such a blocking effect also applies to ' $i{ }_{\mathrm{H}}$ and $g i$ ' constructions, both of which are selected by different types of high-order evaluative predicates, nahriq and balaiq. As with ru', linkers ' $i_{\mathrm{H}}$ and $g i$ ' can take finite clauses, pseudo-cleft clauses, and topic clauses as their complements. Examples for ' $i{ }_{H}$ and gi' are shown in (38) and (39), respectively. 
(38) a. nahriq_'i'_si-pakati' = su'_ku'_qulih

pitiful_LNK_CA-throw.away_ABS_fish

It is a pity that you threw the fish away.

(Finite clause)

b. nahriq_'i'_nanuan_ku'_si-pakati' = su'

pitiful_LNK_what_ABS_CA-throw.away $=2$ S.ABS

Did you ever throw away something that you later regretted?

Lit. What was the thing that you threw away and you later

regretted?

(Pseudo-cleft clause)

c. nahriq_'i'_qulih_ga'_si-pakati' = su'

pitiful_LNK_fish_TOP_CA-throw.away $=2 \mathrm{~S}$.ABS

It is a pity that you threw away the fish.

(Topic clause)

(39) a. balaiq_gi'_c $<$ um $><$ in $>$ bu'_cu'_bauwak_'i'_watan

good_LNK_shoot $<\mathrm{AV}>\langle\mathrm{PERF}>$ _OBL_pig_ABS_Watan

Fortunately, Watan shot a pig.

(Finite clause)

b. balaiq_gi__ima'_ku'_c $<$ um $><$ in $>$ bu'_cu'_bauwak

good_LNK_who_ABS_shoot $<\mathrm{AV}>\langle\mathrm{PERF}\rangle$ _OBL_pig

Who fortunately shot a pig? (Pseudo-cleft clause)

c. balaiq_gi'_watan_ga'_c $<$ um $><$ in $>$ bu'_cu'_bauwak

good_LNK_Watan_TOP_shoot $\langle\mathrm{AV}\rangle\langle\mathrm{PERF}\rangle$ _OBL_pig

Watan is the one who fortunately shot a pig. (Topic clause)

The examples in (40a-b) show that the wh-elements nanuan in (38b) and 'ima' in (39b) are prohibited from extraction in the ' $i_{\mathrm{H}}^{\prime}$ clause and the gi' clause. Topic extraction is also disallowed. The topic DPs qulih in (38c) and watan in (39c) fail to undergo extraction in the ' $i{ }^{\prime}$ H clause and the gi' clause, as in (41a) and (41b).

(40) a. "nanuan_ku'_nahriq_'i'_p $<$ in $>$ akati' = su' what_ABS_pitiful_LNK_throw.away $<$ PERF $>$ UV $>=2$ S.GEN

b. "'ima'_ku'_balaiq_gi'_c $<$ um $><$ in $>$ bu'_cu'_bauwak who_ABS_good_LNK_shoot $<\mathrm{AV}><\mathrm{PERF}>$ _OBL_pig

(41) a. "qulih_ga'_nahriq_'i'_pa-pakati' = su' fish_TOP_pitiful_LNK_RED.CA.IRR-throw.away $=$ 2S.GEN

b. "watan_ga'_balaiq_gi'_c $<$ um $><$ in $>$ bu'_cu'_bauwak Watan_TOP_good_LNK_shoot $<\mathrm{AV}>\langle\mathrm{PERF}>$ _OBL_pig

Moreover, clitic climbing is also prohibited in $r u,{ }^{\prime}{ }^{\prime}{ }_{\mathrm{H}}$, and $g i$ ' constructions. As shown in (42b), (43b), and (44b), the pronominal clitics $=s u^{\prime}$ and $=m u$ are not allowed to move out of the embedded clauses ${ }^{\mathrm{p}}$.

(42) a. lungulung-un $=m u \_r u ' \_m<i n>u a h=s u^{\prime} \_i^{\prime} \_$runi_cuhisa'

think-UV $=1$ S.GEN_LNK_come $<$ PERF $>$.AV $=$

2S.ABS_LOC_here_yesterday

I thought you came here yesterday. 
b. "lungulung-un $=$ misu'_ru'_m $<$ in $>$ uah_i'_runi_cuhisa'

think-UV = 1S.GEN.2S.ABS_LNK_come $<$

PERF > .AV_LOC_here_yesterday

(43) a. nahriq_i'_pa-pakati' = su'_ku'_qulih

pitiful_LNK_RED.CA.IRR = throw.away $=2$ S.GEN_ABS_fish

It is a pity that you will throw the fish away.

b. * nahriq = su'_i'_pa-pakati'_ku'_qulih

pitiful $=$ throw $\cdot$ away $=2 S \cdot G E N \_L N K \_$RED.CA.IRR_ABS_fish

(44) a. balaiq_gi'_ini' $=m u \_b u '-i \_k u^{\prime} \_$bauwak good_LNK_NEG = 1S.GEN__shoot-UV.IMP_ABS_pig

Fortunately, I was not hit by the stone.

b. 'balaiq = mu__i'_ini'_bu'-i_ku'_bauwak

$\operatorname{good}=1 S . G E N \_$LNK_NEG_shoot-UV.IMP_ABS_pig

This evidence shows that in any case, constituents are not allowed to move out of complement clauses headed by the high linkers $r u{ }^{\prime},{ }^{\prime}{ }_{\mathrm{H}}$, and $g i$ '. From this evidence, one question arises: what motivates the blocking effect? It is evident that the blocking effect can be attributed to the complement selection of the matrix predicate. In Mayrinax Atayal, the cognition verb langlung and the high-order evaluative predicates nahriq and balaiq may c-select finite island complements introduced by $r u,{ }^{\prime}{ }_{\mathrm{H}}$, and $g i$ ', respectively. Historically, these finite complementizers were derived from different syntactic categories: $r u$ ' from conjunctions, ' $i$ ' from case markers, and gi' from subordinators (Liu 2011). In this sense, these linkers somehow retain islandhood when they occur as complementizers in high-linking constructions, and thus the blocking effect ${ }^{\mathrm{q}}$ is observed.

Linker properties are conditioned by the selection restrictions imposed by matrix predicates. Matrix predicates determine the syntactic category of their complements, and the complement structure in turn determines the linker status. Regarding island complements, it has been suggested that Mayrinax high linkers bear syntactic properties that should be distinguished from normal complementizers. Under a minimalist framework, the selected high linkers surface as weak complementizers that form weak (defective) phases that are not designated an EPP feature (cf. Basse 2008). Without an EPP feature, a weak complementizer cannot provide an escape hatch for DP constituents, and thus blocks any argument movement. This selectional relationship among matrix predicates, their selected complements, and linkers is illustrated in (45).

(45) High-order evaluative: balaiq/'aqih $\left[\mathrm{CP}_{\text {island }}\left[\mathrm{C}_{\text {gi' }}^{0}\right.\right.$ [no EPP $][+$ tense $\left.]\right]$

$$
\text { Cognition verb: langlung } \quad\left[\mathrm{CP}_{\text {island }}\left[\mathrm{C}_{\mathrm{ru}}^{0} \text { [no EPP }[\text { [+tense }]\right]\right.
$$

In (46a), the linker ' $i{ }_{\mathrm{H}}$ heads a pseudo-cleft clause, in which the $k u$ '-marked clause is a headless relative clause (Tsai 2003) ${ }^{\mathrm{r}}$. 


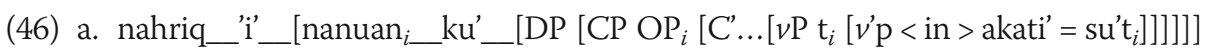
pitiful_LNK_what_ABS_throw.away $<$ PERF.UV $>=2$ S.GEN

Did you ever throw away something that you later regretted?

Lit. What was the thing that you threw away and you later regretted?

b. "nanuan ${ }_{i \_}$ku'_[DP $\left[\mathrm{CP} \mathrm{OP} i\left[\right.\right.$ C'nahriq_[CP OP ${ }_{i}^{\prime} \mathrm{i}$ '_p $<$ in $>$ akati' $=$ su' $\left.\left.\left._{i}\right]\right]\right]$

what_ABS_pitiful_LNK_throw.away $<$ PERF.UV $>=2$ S.GEN

The covert movement taking place in the pseudo-cleft clause (bracketed in 46a) is structurally represented in Fig. 3.

The extraction restriction (Aldridge 2008; Rackowski 2002; Rackowski and Richards 2005) stipulates that only the absolutive DP can undergo wh-extraction. As shown in Fig. 3, there is a CP embedded in the DP. In (46a), the wh-nominal nanuan is not truly extracted from the $k u$ '-marked clause. In fact, the pseudo-cleft clause involves a covert operator movement (Tsai 2003) in which an operator, representing the internal argument (the patient of pinakati), moves to the SPEC of the CP to co-index with nanuan in the matrix predicate position. In his Multiple Spell-Out model, Chomsky $(1995,2001,2007)$ argued that movement takes place cyclically and proceeds not only through $\mathrm{CP}$ but also through $v \mathrm{P}$. According to the T-type ergative analysis in Aldridge (2004; cf. Aldridge 2008), the transitive $v$ in the cleft clause carries an EPP feature and the T bears a structural absolutive case feature. When $v$ carries an EPP feature, the DP operator is raised to the $v \mathrm{P}$ phase edge to check off the [EPP] and is valued as the [ABS] feature from $\mathrm{T}$. In doing so, it is visible to a probe in the next higher phase, $\mathrm{CP}$, and it is eligible to undergo further movement. The $[\mathrm{Q}]$ and $[\mathrm{EPP}]$ features on the $\mathrm{C}^{0}$ are thus able to trigger the DP operator to move to the SPEC of the CP position and make a successful co-indexation. By contrast, the diagram in Fig. 4 represents the ungrammatical sentence in (46b), which is in violation of the Minimal Link Condition (MLC) and locality.

The wh-nominal nanuan cannot undergo relativization in (46b). The fact of the matter is that in covert movement such as in Fig. 4, the DP operator is not allowed to move to the SPEC of the highest CP to make a co-indexation with nanuan. The high linker ${ }^{\prime}{ }_{\mathrm{H}}$, occupying the head position of the lower $\mathrm{CP}$, should function as a phase and provide an escape hatch. As a weak complementizer, however, ${ }^{\prime}{ }_{\mathrm{H}}$ does not carry an EPP feature that triggers movement. Without moving to the edge position of the first phase, the DP operator is unlikely to undergo further movement to the next phase edge and the derivation crashes. The same syntactic operation can apply to other high linkers, such as gi' and $r u$ '.

\subsubsection{Mid linkers selected as strong complementizers}

Cognition verbs, utterance verbs, and epistemic/evidential modals may select complements headed differently by six linkers in Mayrinax Atayal: $n a, g a, m h a, k i{ }_{\mathrm{M}},{ }^{\prime}{ }^{\prime}{ }_{\mathrm{M}}$, and $c u_{\mathrm{M}}^{\prime}$, labeled mid linkers in this paper (cf. Liu 2011). Due to space restraints, the

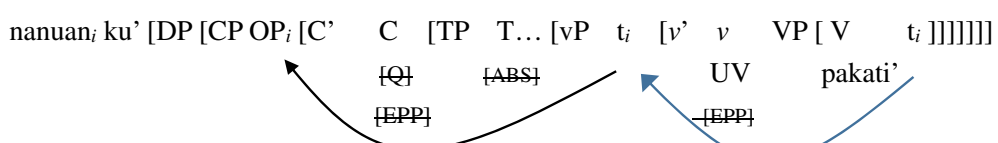

Fig. 3 Covert movement in Example (46a) 


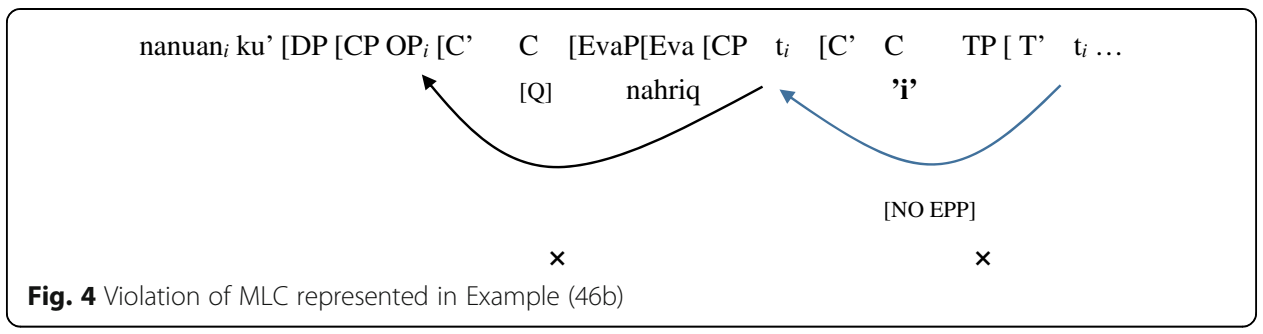

examples in (47) demonstrate only some of these mid linkers. As shown in (47), these mid-linker-introduced complements are finite clauses.

(47) a. ki'i_'i'_ba-bu'-un_ni'_watan_ku'_bauwak possible_LNK_RED-shot-UV_GEN_Watan_ABS_pig

It is possible that Watan will shoot the pig.

b. snuaw-un =mu_cu'_m-a-'uwah_'i'_casan_'i'_hiya' believe-UV $=$ 1S.GEN_LNK_AV-IRR-come_FUT_tomorrow_ABS_3S

I believe that he will come tomorrow.

c. asi_ga'_'iqaat_pa-ptauwaw_'i'_casan_'i'_watan seem_LNK_NEG_IRR-work.AV_FUT_tomorrow_ABS_Watan It seems that Watan will not work tomorrow.

In addition, a mid-linker-introduced clause can be a wh-cleft, as in (48), or a topic clause, as in (49), as can be observed in the high-linking construction aforementioned.

(48) a. ki'i_'i'_nanuan_ku'_ba-bu'-un_ni'_watan possible_LNK_what_ABS_RED-shoot-UV_GEN_Watan What will Watan probably shoot?

b. snuaw-un =su'_cu'_'ima'_ku'_m-a-'uwah_'i'_casan believe-UV $=2 S$.GEN_LNK_who__ABS_AV-IRR-come_FUT_tomorrow Who do you believe will come tomorrow?

c. asi_ga'_'ima'_ku'_'iqaat_pa-ptauwaw_'i'_casan seem_LNK_who_ABS_NEG_IRR-work.AV_FUT_tomorrow Who will be unlikely to work tomorrow?

(49) a. ki'i_'i'_bauwak_ga'_ba-bu'-un_ni'_watan possible_LNK_pig_TOP_RED-shoot-UV_GEN_Watan It is possible that the pig is what Watan will shoot.

b. snuaw-un =mu_cu'_'ihiya'_ga'_m-a-'uwah_'i'_casan believe-UV $=$ 1S.GEN_LNK_3S_TOP_AV-IRR-come_FUT_tomorrow I believe that he is the one who will come tomorrow.

c. asi_ga'_watan_ga'_'iqaatpa-ptauwaw_'i'_casan seem_LNK_Watan_TOP_NEG_IRR-work.AV_FUT_tomorrow It seems that Watan is the one who will not work tomorrow. 
Unlike a high-linking construction, however, wh-extraction or topic extraction is not prohibited in a mid-linking construction. A wh-nominal may undergo extraction from clauses headed by a mid linker, as in (50). The extraction of a topic nominal from embedded clauses of mid linkers is also allowed, as in (51).

(50) a. nanuan_ku'_ki'i_'i'_ba-bu'-un_ni'_watan

what_ABS_possible_LNK_RED-shoot-UV__GEN_Watan

What will Watan probably shoot?

b. 'ima'_ku'_snuaw-un = su'_cu'_m-a-'uwah_i'_casan

who__ABS_believe-UV $=2 \mathrm{~S} . \mathrm{GEN} \_$LNK_AV-IRR-come_FUT_tomorrow

Who do you believe will come tomorrow?

c. 'ima'_ku'_asi_ga'_'iqaat_pa-ptauwaw_i'_casan

who_ABS_seem_LNK_NEG_IRR-work.AV_FUT_tomorrow

Who will be unlikely to work tomorrow?

(51) a. bauwak_ga'_ki'i_'i'_ba-bu'-un_ni'_watan

pig_TOP_possible__LNK_RED-shoot-UV_GEN_Watan

The pig is what Watan will likely shoot.

b. 'ihiya'_ga'_snuaw-un =mu_cu'_m-a-'uwah_'i'_casan

3S_TOP_believe-UV $=1 \mathrm{~S} . \mathrm{GEN} \_$LNK_AV-IRR-come_FUT_tomorrow

I believe that he is the one who will come tomorrow.

c. watan_ga'_asi__ga'_iqaat_pa-ptauwaw_i'_casan

Watan_TOP_seem_LNK_NEG_IRR-work.AV_FUT_tomorrow

It seems that Watan is the one who will not work tomorrow.

Furthermore, clitic climbing is also allowed. The clitic $=m u$ base-generated in an ' $i_{\mathrm{M}^{-}}$ complement clause may also attach to the epistemic modal ki' $i$, as in (52b). In (53b), the second-person singular genitive pronoun $=s u^{\prime}$ may bypass the mid linker $c u_{M}^{\prime}$ and attach to the first verb.

(52) a. ki'i_'i'_ba-bu'-un = mu_ku'_bauwak

possible_LNK_RED-shot-UV = 1S.GEN_ABS__pig

I will probably shoot the pig.

b. ki'i= mi'_ba-bu'-un_ku'_bauwak

possible = 1S.GEN.LNK_RED-shot-UV_ABS_pig

I will probably shoot the pig.

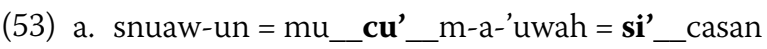

believe-UV = 1S.GEN_LNK_AV-IRR-come = 2S.ABS.FUT_tomorrow

I believe that you will come tomorrow.

b. snuaw-un = misu'__u'm-a-'uwah_'i'_casan

believe-UV = 1S.GEN.2S.ABS_LNK_AV-IRR-come_FUT_tomorrow

I believe that you will come tomorrow.

The examples in (50) to (53) show that a specific category of verbal predicates may select finite complement clauses in which the blocking effect does not take 
place. Just as in English, non-factive verbs (e.g., "think/say") select "that" complements that do not exhibit the blocking effect (Basse 2008; Varlokosta 1994) s $^{\mathrm{s}}$ In this sense, the mid linkers that introduce these non-blocking complements are canonical finite complementizers (Liu 2011; Tang 1999). Under minimalist analysis, these selected mid linkers are strong complementizers that are structurally designated an EPP feature that triggers the movement of constituents. With an EPP feature, a strong complementizer can provide an escape hatch for DP constituents. The selectional relationship among matrix predicates, their selected complements, and mid linkers is illustrated in (54).

(54) Evidential predicate:

Utterance verb:

Cognition verb:

Cognition verb:

Cognition verb:

Epistemic modal:

Epistemic modal:

asi $_{\text {evid }}$
kumaal
'ua' $\left[\mathrm{CP}_{\text {finite }}\right.$
snuawun
mai'cug
ki'i
asi $_{\text {epis }}$

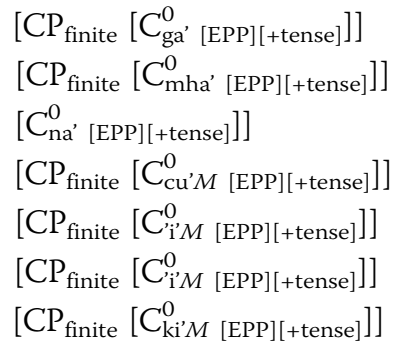

The following sentences in (55) show how Mayrinax mid-linking construction is structurally derived and how the DP extraction is operated. Sentence (55a) is structurally represented by Fig. 5 .

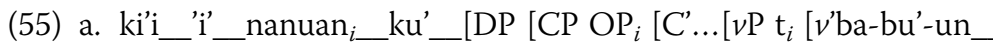
possible_LNK_what_ABS_RED-shoot-UV_ ni'_watant $\left.\left.{ }_{i}\right]\right]$ ]]

GEN_Watan

What will Watan probably shoot?

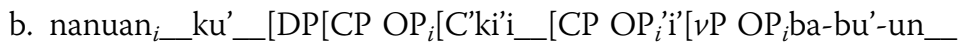
what_ABS_possible_LNK_RED-shoot-UV_

ni'_watant $\left.t_{i}\right]$ ]]

GEN_Watan

What will Watan probably shoot?

In (55a), the mid linker ' $i_{M}^{\prime}$ introduces a wh-cleft, in which a covert movement takes place. Within the headless relative clause marked by the absolutive $k u$, an operator representing the internal argument moves to the SPEC of the CP to co-index with nanuan in the matrix predicate position. This movement takes place successively and cyclically. According to Chomsky (2001), movement accords with the locality condition achieved in the Phase Impenetrability Condition (PIC).

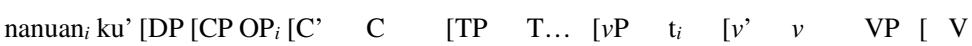

$\left.\left.\left.\left.\left.\mathrm{t}_{i}\right]\right]\right][]\right]\right]$

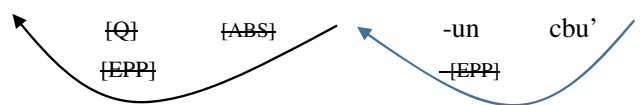

Fig. 5 Covert movement in Example (55a) 
(56) Phase Impenetrability Condition (Chomsky 2001: 5)

Only the edge of a phase $(\nu \mathrm{P}, \mathrm{CP})$ is accessible to operations.

The PIC dictates the movement of arguments, which must first pass through the edge of the $v \mathrm{P}$. In the object wh-movement, $v$ has an EPP feature that triggers the object DP to the $v \mathrm{P}$ specifier position. Having been located at the edge of the $v \mathrm{P}$, the object becomes accessible to a probe in the next phase $(\mathrm{CP})$ and can undergo further movement. Based on T-type ergative analysis (Aldridge 2004), in the cleft clause the T carries a structural absolutive case feature and the transitive $v$ carries an EPP feature. When $v$ carries an EPP feature, the DP operator is raised to the $v \mathrm{P}$ phase edge to check off [EPP] and is valued as the ABS case feature from T. At the $v \mathrm{P}$ edge position, the DP operator is visible to a probe in the next higher $\mathrm{CP}$ phase. The $[\mathrm{Q}]$ feature and the [EPP] feature on the $\mathrm{C}^{0}$ thus trigger the DP operator to the SPEC of the $\mathrm{CP}$ position.

The diagram in Fig. 6 represents the structure of (55b). In (55b), the wh-nominal can be further extracted, indicating that there are multiple layers of $\mathrm{CP}$ embedded in the $k u^{\prime}$-marked complex DP. In the covert movement in Fig. 6, the DP operator must move successively and cyclically to the SPEC of the highest CP to make a co-indexation with nanuan in the matrix predicate position. According to the PIC, the DP operator must first pass through the edge of the lower $\mathrm{CP}$ before landing at the edge of the highest $\mathrm{CP}$. It has been suggested that the mid linker ' ${ }^{\prime}{ }_{M}$ may serve as a true complementizer, occupying the head position of the lower $\mathrm{CP}$. As a strong complementizer, ' $i{ }_{M}$ carries an EPP feature that triggers DP movement. As a result, the mid linker may host a wh-operator in its SPEC position. Being at the edge position of the first phase, the operator is eligible for another movement to the next phase. The same analysis can be carried over to other types of mid linkers.

It is noteworthy that in some cases mid linkers seem to block wh-extraction. Recall that wh-nominals can be extracted from embedded clauses headed by a mid linker, such as $c u_{M}^{\prime}$ in (57). The wh-nominal 'ima' in (57a) represents the extracted agent, nanuan in (57c) the extracted patient, and nanuan in (57d) the extracted instrument in the embedded clauses. These embedded wh-nominals successfully undergo extraction when the matrix verb surfaces as its UV form, as in (57b), (57d), and (57f).

(57) a. snuaw-un = su'_cu'_'ima'_ku'_m-a-'uah_'i'_casan believe-UV $=$ 2S.GEN_LNK_who_ABS_AV-IRR-come_FUT_tomorrow Who do you believe will come tomorrow?

b. b.'ima'_ku'_snuaw-un = su'_cu'_m-a-'uwah_'i'_casan who_ABS_believe-UV $=2$ S.GEN_LNK_AV-IRR-come_FUT_tomorrow Who do you believe will come tomorrow?

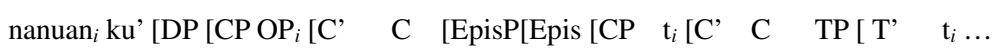
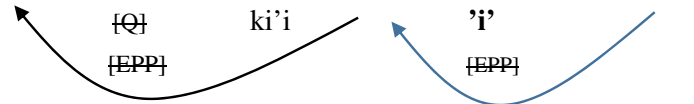

Fig. 6 Covert movement in Example (55b) 
c. snuaw-un = su'_cu'_nanuan_ku'_niq-un_ni'_watan

believe-UV $=2 S . G E N \_$LNK_what_ABS_eat-UV_GEN_Watan

What do you believe Watan ate?

d. nanuan_ku'_snuaw-un = su'_cu'_niq-un_ni'_watan

what_ABS_believe-UV $=2 S \cdot G E N \_L N K \_$eat-UV_GEN_Watan

What do you believe Watan ate?

e. snuaw-un = su'_cu'_nanuan_ku'_si-tuting_ni'_watan_cku'_xuil

believe-UV = 2S.GEN_LNK_ what_ABS_CA-

hit_GEN_Watan_OBL_dog

What do you believe Watan used to hit the dog?

f. nanuan_ $k u^{\prime} \_$snuaw-un $=$su'_cu'_si-tuting_ni'__watan__cku'_xuil

what_ABS_believe-UV $=2 \mathrm{~S} \cdot \mathrm{GEN} \_$LNK_CA-

hit_GEN_Watan_OBL_dog

What do you believe Watan used to hit the dog?

However, if the first verb shifts to an AV form, the wh-extraction from the embedded clause is not feasible, as shown in (58b), (58d), and (58f).

(58) a. $\mathrm{s}<\mathrm{um}>$ nawuaw $=\mathrm{su}^{\prime} \_\mathbf{c u} \_$'ima'_ku'_m-a-'uah_'i'_casan

believe $<$ AV $>=2$ S.ABS_LNK_ who__ABS_AV-IRR-

come_FUT_tomorrow

Who do you believe will come tomorrow?

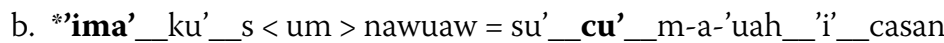

who__ABS__believe $<$ AV $>=2 S$.ABS__LNK_AV-IRR-

come_FUT_tomorrow

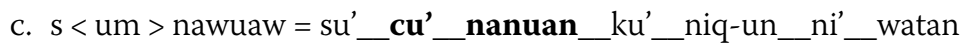

believe $<$ AV $>=2$ S.ABS_LLNK_what_ABS_eat-UV_GEN_Watan

What do you believe Watan ate?

d. 'nanuan_ku'_s $<$ um $>$ nawuaw $=$ su'_cu'_niq-un_ni'_watan

what_ABS_believe $<\mathrm{AV}\rangle=2 \mathrm{~S}$.ABS_LNK_eat-UV_GEN_Watan

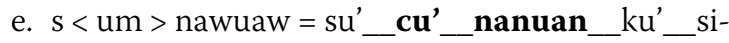

tuting_ni'_watan_cku'_xuil

believe $<\mathrm{AV}>=2 \mathrm{~S}$.ABS_LNK_what_ABS_CA-

hit_GEN_Watan_OBL_dog

What do you believe Watan used to hit the dog?

f. 'nanuan_ku'_s $<$ um $>$ nawuaw $=\mathrm{su}_{\text {___ }} \mathbf{c u}_{\text {'_ }}$ si-

tuting_ni'_watan_cku'_xuil

what_ABS_believe $<\mathrm{AV}>=2 \mathrm{~S}$.ABS_LNK_CA-

hit_GEN_Watan_OBL_dog

In examining how the blocking effect takes place, it was found that in actuality, the blocking effect is not caused by the linker property but can be attributed to a violation of locality. The ill-structured sentence in (58b) is diagramed in Fig. 7.

In order to make a co-indexation with the wh-nominal 'ima', a DP operator (representing the matrix argument in the embedded clause) that is placed at the SPEC of the lower CP must arrive at the SPEC of the higher CP. In (58b), the cognition verb sumnawuaw is in the 


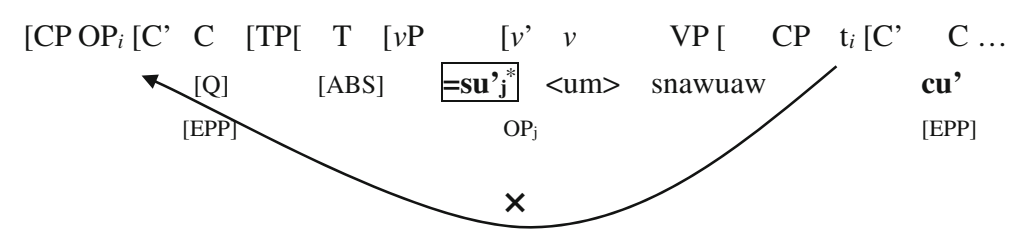

Fig. 7 Covert movement in Example (58b) in violation of locality

*Although operated in the head movement, clitic climbing may involve argument dependency-a clitic pronoun is somehow associated with an argument position (Kayne 1989, 1993). It is noteworthy that in Mayrinax the absolutive clitic pronoun =su' may have a null reflex/operator (OPj in Fig. 7) in its argument position that blocks movement of an $\mathrm{A}^{\prime}$-element (OPi), and the blocking effect makes the clitic pronoun look like a DP argument. Further investigation of how a clitic moves or climbs and how clitic climbing is different from $A^{\prime}$-movement or $A^{\prime}$-movement in structural representation is needed to tackle this problem

AV form. Since Mayrinax Atayal exhibits an ergative pattern, an AV verb is intransitive. In an intransitive AV clause, T bears an [ABS] feature, which will be probed and will be valued downward onto the closest argument (Aldridge 2008). The best candidate for the [ABS] feature is the external argument $=s u^{\prime}$ at the SPEC of the $v \mathrm{P}$ position. The $=s u^{\prime}$ will later be triggered to move to the SPEC of the higher CP by the [Q] and the [EPP] features on the higher $C^{0}$. This means that it should be the external argument of the matrix clause that can undergo wh-extraction, but not the DP operator representing the matrix argument from the embedded clause. If the DP operator (i.e., the matrix argument from the embedded clause) moves to the matrix [SPEC, CP] position, this movement will violate the MLC stipulated in the probe-goal relationship. The structure of the grammatical sentence in (57b) is represented in Fig. 8.

In (57b), the embedded matrix argument can be wh-extracted because its operator makes a successful co-indexation with the wh-argument 'ima'. In this case, the matrix cognition verb is in its transitive (UV) form. In the T-type ergative syntax, the $\mathrm{T}$ carries an [ABS] feature and the transitive $v$ bears both an [EPP] and an inherent genitive case feature that is assigned to the external argument $=s u$ '. By receiving the genitive case, the external argument is no longer a target for the probe. The transitive $v$ thus targets the matrix argument from the embedded clause; that is, the operator that merges at the SPEC of the lower $\mathrm{CP}$. In the next steps, the operator passes through two phase edges- $[\mathrm{SPEC}, \nu \mathrm{P}]$ and $[\mathrm{SPEC}$, higher $\mathrm{CP}$ - by checking off the [EPP] on the transitive $v$, the $[\mathrm{ABS}]$ on the $\mathrm{T}$, and the [Q] and the $[E P P]$ on the higher $C^{0}$, and finally lands in the SPEC position of the higher $C P$.

\subsubsection{Low linkers}

In addition to high- and mid-linking constructions, Mayrinax has various types of non-finite constructions, including deontic constructions, tough/middle constructions, low adverbial verb constructions, subject and object control constructions, and resultative constructions. As discussed previously, these non-finite constructions are selected by different complement-taking verbs and are headed by the low linkers $k i_{\mathrm{L}}{ }^{\prime}, i_{\mathrm{L}}$, and $c u_{\mathrm{L}}^{\prime}$. This section will examine the syntactic status(es) that low linkers occupy. Low-linking constructions can

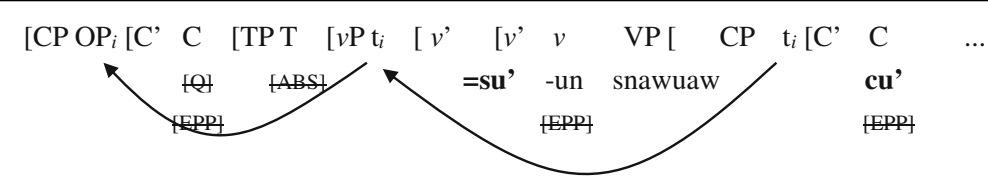

Fig. 8 Covert movement in Example (57b) 
be further divided into two types: $k i_{\mathrm{L}}^{\prime}$ constructions and $i_{\mathrm{L}}^{\prime} / c u_{\mathrm{L}}^{\prime}$ constructions; $k i_{\mathrm{L}}^{\prime}$ constructions are sensitive to extraction patterns, while the ${ }^{\prime}{ }_{\mathrm{L}} / \mathrm{cu}_{\mathrm{L}}^{\prime}$ constructions are not.

3.2.4.1 Low-linking construction sensitive to extraction patterns The deontic modal $a s i_{\text {deon }} \mathrm{c}$-selects a non-finite complement introduced by the type A low linker $k i_{\mathrm{LA}}^{\prime}$ (see also $\mathrm{Yu}$ 2015). The $k i_{\mathrm{LA}}^{\prime}$-introduced complement syntactically behaves like complements of mid-linking constructions and allows the extraction of the embedded arguments. The linker $k i_{\mathrm{LA}}^{\prime}$ can introduce a pseudo-cleft clause and a topic clause, as in (59).

(59) a. asi_ki'_nanuan_ku'_pumua'-un = nia'

DEON_LNK_what_ABS_plant-UV $=3$ S.GEN

What must he plant?

b. asi_ki'_bunga'_ga'_pumua'-un = nia'

DEON_LNK_sweet.potato__TOP_plant-UV = 3S.GEN

It is the sweet potato that he must plant.

Wh-extraction and topic extraction is not prohibited in $k i_{\mathrm{LA}}^{\prime}$ constructions. A whnominal may undergo extraction from embedded $k i_{\text {LA }}$ clauses, as in (60a). The extraction of a nominal topic from the embedded clause is also allowed, as in (60b).

(60) a. nanuan_ku'_asi_ki'_pumua'-un = nia'

what_ABS_DEON_LNK_plant-UV $=3 S$.GEN

What must he plant?

b. bunga'_ga'_asi_ki'_pumua'-un = nia'

sweet.potato_TOP_DEON_LNK_plant-UV = 3S.GEN

It is the sweet potato that he must plant.

Moreover, clitic climbing is not blocked. The clitic pronoun $=m u$ attaching to the embedded verb may also attach to the deontic modal $a s i_{\text {deon }}$, as in (61).

(61) a. asi_ki'_tal-an =mu_ku'_'ulaqi'

DEON_LNK_see-LA $=1$ S.GEN_ABS_child

I must see the child.

b. asi = mu_ki'_tal-an_ku'_'ulaqi'

DEON $=1$ S.GEN_LNK_see-LA_ABS_child

I must see the child.

According to $\mathrm{Yu}$ (2015), the deontic linker $k i_{\mathrm{LA}}^{\prime}$ never co-occurs with the free aspectual marker kia.

(62) Mayrinax Atayal (Yu 2015: 95)

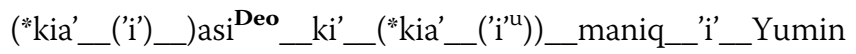

PROG_LNK_must_LNK_PROG_LNK_eat.AV_NOM_Yumin

It is definite that Yumin has meals.

Owing to this co-occurrence constraint, it has been suggested that the linker $k i_{\text {LA }}^{\prime}$ should occur internally in the AspP. The deontic modal $a s i_{\text {deon }}$ structurally c-selects a 
non-finite AspP headed by $k i_{\text {LA }}^{\prime}$. Given the sensitivity to extraction patterns, $k i_{\text {LA }}^{\prime}$ thus occupies the "strong" head position of the AspP (Dai et al. 2010; cf. Yu 2015). The selectional relationship among the deontic modal $a s i_{\text {deon }}$, the selected complement, and the linker is shown in (63).

(63) Deontic modal: $\left[\mathrm{AspP}_{\text {non-finite }}\left[\mathrm{Asp}_{\mathrm{ki} \text { 'LA }}^{0}[\mathrm{EPP}][-\right.\right.$ tense $\left.]\right]$

But how can an aspectual head be sensitive to extraction operations like finite complementizers? More investigation and tests are needed in future research to answer this question.

3.2.4.2 Low-linking Constructions Insensitive to Extraction Patterns Low-linking constructions such as tough/middle constructions, low adverbial verb constructions, subject and object control constructions, and resultative constructions are insensitive to extraction patterns. These constructions are characterized by the Type B and Type C low linkers. In these constructions, a low linker does not introduce finite clauses. In addition, a low linker cannot take a pseudo-cleft clause and a topic clause. Wh-clauses, as in (64), and topic clauses, as in (65), cannot occur after the low linkers.

(64) a. 'm-na-hiyaw_i'__ima'_ku'_h $<$ um $>$ akay

AV-VCL-slow_LNK_who__ABS_walk_AV $>$

Intended: Who walks slowly?

b. 'h < um > akay_cu'_'ima'_ku'_ma-'uway

walk $<\mathrm{AV}>$ _LNK__who__ABS_AV-tired

Intended: Who walked tiredly?

(65) a. "m-na-hiyaw_'i'_watan_ga'_h $<$ um $>$ akay

AV-VCL-slow_LNK__Watan_TOP_walk $<\mathrm{AV}>$

Intended: Watan is the one who walks slowly.

b. "h $<$ um > akay_cu'_watan_ga'_ma-'uway

walk $<\mathrm{AV}>$ _LNK_Watan__TOP_AV-tired

Intended: Watan is the one who walked tiredly.

The examples in (66) demonstrate wh-extraction and the topicalization patterns of a mono-clause. The subject tapas in (66a) undergoes wh-extraction and topicalization, as shown in (66b) and $(66 \mathrm{c})$, respectively.

(66) a. maniq_cu'_qulih__i'_tapas

eat.AV_OBL_fish_ABS_Tapas

Tapas ate fish.

b. 'ima'_ku'_maniq_cu'_qulih

who_ABS_eat.AV_OBL_fish

Who ate fish?

c. tapas_ga,_maniq_cu'_qulih

Tapas_TOP_eat.AV_OBL_fish

Tapas is the one who ate fish. 
Like the extraction pattern of a mono-clause, an extracted argument must move directly to the initial position without staying behind a low linker. Compare the contrasts shown in $(64,67)$ and $(65,68)$.

(67) a. 'ima'_ku'_m-na-hiyaw_'i'_h $<$ um $>$ akay

who_ABS_AV-VCL-slow_LNK_walk $<$ AV $>$

Who walks slowly?

b. 'ima'_ku'_h < um > akay_cu'_ma-'uway

who_ABS__walk $<$ AV $>$ _LNK_AV-tired

Who walked tiredly?

(68) a. watan_ga'_m-na-hiyaw_'i'_h $<$ um $>$ akay

Watan_TOP_AV-VCL-slow_LNK_walk $<$ AV $>$

Watan is the one who walks slowly.

b. watan_ga'_h $<$ um $>$ akay_cu'_ma-'uway

Watan_TOP_walk $<\mathrm{AV}>$ _LNK_AV-tired

Watan is the one who walked tiredly.

It is evident that unlike high and mid linkers, low linkers do not occur as finite complementizers. However, questions remain. If low linkers are not finite $C^{0}$ elements, what functional categories should they belong to? Do they occupy syntactic positions or not? To answer these questions, the constituent sizes of the complements headed by low linkers must be tested and determined. It has been argued that low-linking constructions insensitive to extraction tests can be further divided into two types according to constituency tests.

3.2.4.3 Type B low linkers as non-finite complementizers An object control verb and a tough/middle predicate c-select as the complement a non-finite CP introduced by the type B low linker ' $i_{\mathrm{LB}}^{\prime}$. In these cases, the constituency of the ${ }^{\prime}{ }_{\mathrm{LB}}$ complement should be clausal rather than phrasal. This argument is based on the following evidence. First, in Mayrinax Atayal a non-finite CP can be detached like a finite CP (Koster and May 1982). The examples in (69) and (70) show that ' $i$ ' complements of object control constructions and tough constructions can undergo topicalization.

(69) a. siwal-an_ni'_tapas_'i'_watan__[CP'i'_l $<$ um $>$ anguy]

allow-LA_GEN_Tapas_ABS_Watan_LNK_swim $<$ AV $>$

Tapas allowed Watan to swim.

b. [CP'i'_l $<$ um $>$ anguy]_ga'_siwal-an_ni'_tapas_'i'_watan

LNK_swim $<$ AV $>$ _TOP_allow-LA_GEN_Tapas_ABS_Watan

Lit. As for swimming, Tapas allowed Watan to do

so.

(Object control construction)

(70) a. 'ayhung_[CP'i'_tal-an]_ku'_ruas_ka'_hani hard.AV_LNK_see-LA_ABS_book_NL_this

This book is hard to read. 
b. [CP'i'_tal-an]_ga'_ayhung_ku'_ruas_ka'_hani]

LNK_see-LA_TOP_hard_ABS_book_NL_this

Lit. As for reading, this book is hard to read.

(Tough construction)

The same topicalization process can also apply to the $c u_{M}^{\prime}$ complement, a finite CP, as in (71).

(71) a. baq-un $=m u \_\left[C P c u ' \_m-<\text { in }>\text { uah_'i'_watan] }\right.$

know-UV = 1S.GEN_LNK_AV-come $<$ PERF $>$ _ ABS_Watan

I knew that Watan came.

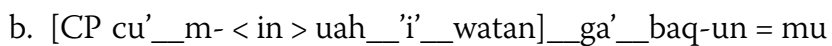

LNK_AV-come $<$ PERF $>$ _ABS__Watan__TOP_know-UV $=1 S . G E N$

As for the fact that Watan came, I knew.

A non-finite CP can undergo an ellipsis like a finite CP. In (72a-b), the complement clauses (' $i$ ' can be omitted in the second conjunct.

(72) a. siwal-an_ni'_tapas_'i'_watan_[CP'i'__l $<$ um $>$ anguy],_

allow-LA__GEN_Tapas_ABS_Watan__LNK__swim $<\mathrm{AV}>$

siwal-an = nia'__i'_yumin,__uwi

allow-LA = 3S.GEN_ABS_Yumin_too

Tapas allowed Watan to swim, and she allowed Yumin to do so,

too.

(Object control construction)

b. 'ayhung_[CP'i'_tal-an]_ku'_ruas_ka'_hani_

hard.AV_LNK_see-LA_ABS_book_NL_this_

'ayhung_ku'_ruas_ka'_haca_'uwi

hard.AV_ABS_book_NL_that_too

This book is hard to read, and that book is hard, too. (Tough construction)

A finite complement clause may also undergo ellipsis. In (73), the $c u_{M}^{\prime}$ complement can be omitted in the second conjunct.

(73) baq-un_ni'_watan_ [CPcu'_m- < in > usa'_ i'_bari

know-UV__GEN_Watan_LNK_AV- $<$ PERF $>$ _LOC_Miaoli_

'i__hiya'],_baq-un_ni'_tapas__uwi

ABS_3S_know-UV_GEN_Tapas_too

Watan knew that he went to Miaoli, and Tapas knew, too.

Under non-finite CP analysis, this Type B low linker heading non-finite complements therefore occurs as a non-finite complementizer. The selectional relationship among the matrix predicate, the selected complement, and the linker is shown in (74). 
(74) tough/middle predicates:

$\left[\mathrm{CP}_{\text {non-finite }}\left[\mathrm{C}_{\mathrm{I}^{\prime} \mathrm{LB}}^{0}[\mathrm{EPP}][-\right.\right.$ tense $\left.]\right]$

object control verbs

object control verbs

A Mayrinax tough construction is structured like that in (75), in which the DP ruas is not base-generated as the internal argument of the embedded verb talan, but instead merges as the external argument of the first verb 'ayhung. In this sense, to co-index with the external DP ruas, a DP operator must move from the internal argument position to the edge position of the embedded ' $i_{\mathrm{LB}}$ clause. The linker ' $i_{\mathrm{LB}}^{\prime}$ here must provide a landing site, such as a SPEC position, for the DP operator.

(75) ['ayhung_[CP OP ${ }_{i}\left[\mathbf{C}^{\prime}\left[\mathbf{C}^{\prime} \mathbf{i}\right.\right.$ __talan-an_ $\left.\left.\left.\mathrm{t}_{i}\right]\right]\right] \mathrm{ku} \mathrm{k}^{\prime} \_\mathrm{ruas}_{i} \_\mathrm{ka} \_$hani]

hard.AV_LNK_see-LA_ABS_book_NL_this

This book is hard to read.

The type $\mathrm{B}$ low linker $' i_{\mathrm{LB}}$ may occupy the head position of a non-finite $\mathrm{CP}$. The covert movement in the tough construction in (75) is simplified in Fig. 9.

Hosting an operator in its SPEC position, ' $i_{\mathrm{LB}}^{\prime}$ is designated an [EPP] feature; ' $i_{\mathrm{LB}}^{\prime}$ is therefore a strong complementizer. Being at the SPEC of the $\mathrm{CP}$, the nominal operator can co-index with ruas base-generated in the matrix clause. The same non-finite $\mathrm{CP}$ configuration and operation in Fig. 9 may also account for the derivation process of the CA object control construction in (76).

(76) si-siwal_ni'_tapas_'i'_watan_ku'_qulih

CA-allow_GEN_Tapas_OBL_Watan_ABS_fish_

$\left[\mathrm{CPOP}_{i}\left[\mathbf{C}^{\prime}\left[\mathbf{C}^{\prime} \mathbf{i} \_\right.\right.\right.$_pa-qaniqt $\left.\left.\left.\mathbf{t}_{\boldsymbol{i}}\right]\right]\right]$

LNK_CAU-eat.AV

Tapas allowed Watan to eat the fish.

Based on Chang (2015), in the CA object control construction the "embedded patient" qulih "fish" is base-generated in the applicative phrase of the matrix clause rather than in the object position of the embedded clause. In this case, to co-index with the matrix DP qulih, an anaphoric DP operator must move from the embedded object position to the edge position of the embedded ' $i$ ' clause. The non-finite complementizer ' $i$ ' LB here provides a SPEC position for the DP operator.

3.2.4.4 Type $C$ low linkers as vP-level complementizers. Adverbial verbs and subject control verbs select non-finite complements that are introduced by the type $\mathrm{C}$ low linker ' $i_{\mathrm{LC}}$, and active verbs in resultative constructions select non-finite complements headed by $c u_{\mathrm{LC}}^{\prime}$. In these cases, the complement size of the linker-introduced constituents can be

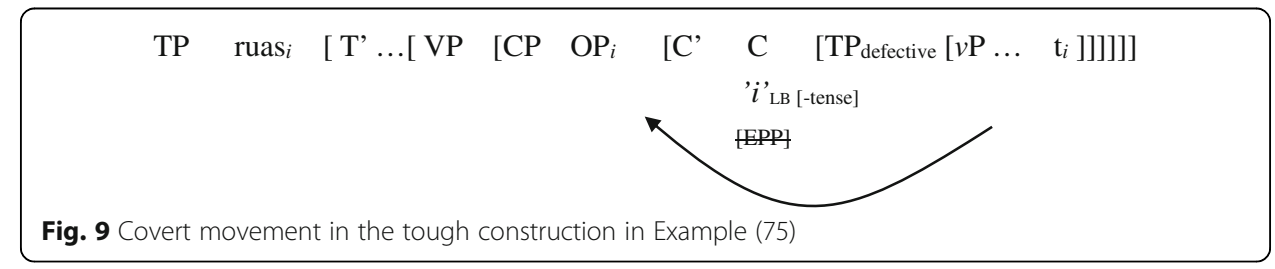


no larger than a $v \mathrm{P}$. To begin with, the embedded verbs in the ' $i_{\mathrm{LC}}$ complement and the $c u_{\mathrm{LC}}^{\prime}$ complement are subject to the AV-only restriction, as in (77a), (78a), and (79a). The embedded complements contain a non-phase intransitive $v \mathrm{P}$, where the $v$ does not bear edge features (Aldridge 2004, 2008). Second, $i_{\mathrm{LC}}^{\prime}$ phrases and $c u_{\mathrm{LC}}^{\prime}$ phrases cannot undergo topicalization like finite and non-finite CPs, as in (77b), (78b), and (79b).

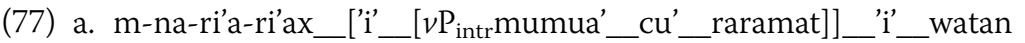
AV-VCL-RED-day_LNK_plant.AV_OBL_vegetables_ABS_ Watan

Watan plants vegetables often. (Low adverbial verb construction)

b. 'i'_mumua'_cu'_raramat_ga'_m-na-ri'a-ri'ax_'i'_watan LNK_plant.AV_OBL_vegetable_TOP_AV-VCL-RED-day_ABS_Watan

(78) a. m-uah_['i'_ $\left[v \mathrm{P}_{\text {intr }}\right.$ mumua'_cu'_raramat $\left.]\right]_{\text {_ }} \mathrm{i}$ '__watan AV-come_LNK_plant.AV_OBL_vegetable_ABS_Watan

Watan came to plant vegetables. (Subject control construction)

b. "'i'_mumua'_cu'_raramat_ga'_m-uah_'i'_watan LNK_plant.AV_OBL_vegetable_TOP_AV-come_ABS_Watan

(79) a. c $<u m>x u^{\prime} \_\left[c u \text { __ }\left[v \mathrm{P}_{\text {intr }} \text { maspaqpaq_cu'_buax_] }\right]\right.$ smash $<\mathrm{AV}>$ _LNK__broken.AV__OBL__rice_ 'i'_watan

ABS_Watan

Watan smashes the rice into pieces. (Resultative construction)

b. 'cu'_maspaqpaq_ga',_c $<$ um $>$ xu'_cu'_buax_'i'_watan LNK_broken.AV_TOP_smash $\langle\mathrm{AV}\rangle$ _OBL_rice_ABS_Watan

Third, these linker-introduced phrases cannot undergo ellipsis, which can be attested in both finite and non-finite CPs. As shown in (80), linker phrases cannot be omitted in the second conjunct.

(80) a. "m-na-ri'a-ri'ax_'i'_mumua'_cu'_raramat_'i' AV-VCL-RED-day_LNK_plant.AV_OBL_vegetables_ABS_ watan,_m-na-ri'a-ri'ax_'i'_tapas,_'uwi Watan_AV-VCL-RED-day_ABS_Tapas_too Intended: Watan often plants vegetables, and Tapas often does so, too.

b. "'a-'usal-an_'i'_c $<$ um $>$ bu'_ni'_watan_ RED-go-LA_LNK_shoot $<$ AV $>$ _ GEN_Watan_ ku'_bauwak,_'a-'usal-an =mu_ku'_bauwak,_'uwi ABS_pig_RED-go-LA = 1S.GEN_ABS_pig_too Intended: Watan will go shooting the pig, and I will, too.

c. 'c $<$ um $>$ xu'_cu'_maspaqpaq_cu'_buax_ smash $<\mathrm{AV}>$ _LNK_broken.AV_OBL_rice_ 'i'_watan,_c $<$ um $>$ xu'_'i'_tali'_'uwi ABS_Watan_smash $<\mathrm{AV}>$ _ABS_Tali_too Intended: Watan smashes the rice into pieces, and Tali does so, too. 
Given that syntactic diagnostics targeting the finite or non-finite complement clauses do not target the $v$ P-layer type $\mathrm{C}$ low-linker phrases, the type $\mathrm{C}$ low linkers cannot be treated on a par with the non-finite $\mathrm{C}^{0}$ element like the type $\mathrm{B}$ low linkers, so what functional category do they belong to? First, the aspectual head analysis is untenable because $\nu$ P-level linkers are irrelevant to aspectual expressions (cf. Chen 2010). Can they be morphological light verbs $p a$ - and $k a$ - with verbal semantic contents? The answer is also negative. Unlike morphological light verbs, which denote action, state, or change-of-state, low linkers do not have any semantic content. They also do not behave like a voice marker, which exerts a feature-agreement relationship between the $v^{0}$ and the DP.

It has been suggested that the type $C$ low linkers ${ }^{\prime}{ }_{\mathrm{LC}}$ and $c u_{\mathrm{LC}}^{\prime}$ be better analyzed as $v$ P-layer complementizers that are specialized for intransitive $v$ Ps. These $v \mathrm{P}$-layer complementizers occur $v$ P-internally, occupying the head position. Without being designated an EPP feature, these $\nu$ P-layer linkers are defective complementizers related to non-phase intransitive $v$ Ps. The selectional relationship among the matrix verbs, the complements, and the selected low linkers is demonstrated in (81).

(81) Low adverbial verb/ subject control verb:

Resultative action verb:

$$
\begin{aligned}
& {\left[v \mathrm{P}_{\text {intr }}\left[v \mathcal{C}_{\mathrm{i}^{\prime} \mathrm{LC}} \text { [no EPP][-tense][non-phase] }\left[\mathrm{VP}_{\text {intr }}\right]\right]\right]} \\
& {\left[\nu \mathrm{P}_{\text {intr }}\left[\nu c_{\text {cu'LC }} \text { [no EPP][-tense] [non-phase] }\left[\mathrm{VP}_{\text {intr }}\right]\right]\right]}
\end{aligned}
$$

The following will illustrate how a low-linking construction is derived using $v$ P-layer complementizer analysis. An NAV adverbial verb construction like that in 82 represents a restructuring process where long-distance object movement is attested. The structure is shown in Fig. 10 (cf. Chen 2012).

(82) 'an-ri-ri'ax-un $=$ nia' $\_\left[\nu \mathrm{P}_{\text {intr }}{ }^{\prime} \mathrm{i}^{\prime} \_\left[\nu \mathrm{P}_{\text {intr }} \text { maniq } \_\mathbf{t}_{i}\right]\right] \mathrm{ku}$ ' $_{\text {qulih }}$

VCL-RED-day-UV (often) $=3 S$.GEN_LNK_eat.AV_ABS_fish

He often ate the (kind of) fish.

As shown in (82), the qulih "fish" base-generated in the embedded object position finally ends up as the matrix $\mathrm{ABS}$ argument. In the restructuring process, the intransitive $v$ and the defective $v$ P-layer complementizer do not form phases. Moreover, they do not constitute full-fledged projections for extraction operations and are insensitive to feature valuation or feature checking. Triggered by the EPP feature on the matrix transitive $v$, the embedded object qulih thus directly moves to the SPEC of the matrix $v \mathrm{P}$ and is valued as the ABS feature from T.

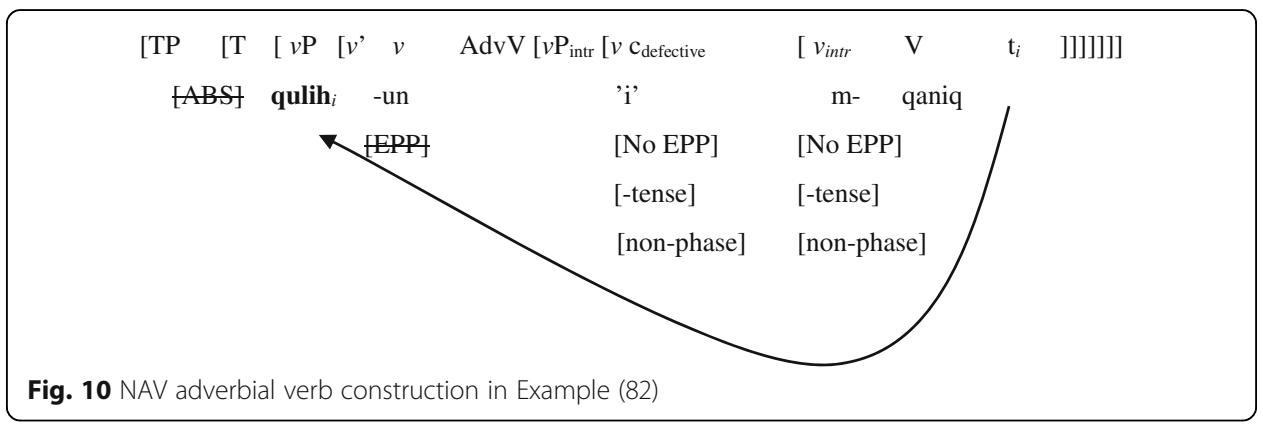




\section{Predicate hierarchy and linker cartography}

Table 3 refines and reorganizes the selectional relationship between the complementtaking verbs/predicates and their selected linkers, which have been recategorized in three syntactic levels, from high to low.

Table 4 summarizes three classes of Mayrinax complement-taking verbs/predicates and categorizes three layers of the selected linkers with respect to their structural heights in the syntactic hierarchy. Each class of predicates and linkers patterns with complements that differ in their constituency and syntactic properties.

High-order evaluative verbs and factive cognition verbs ("think $\mathrm{v}^{\mathrm{v}} / \mathrm{know}^{\text {") }} \mathrm{c}$-select finite island complements headed by the high linkers ' $i{ }_{\mathrm{H}}, g i$ ', and $r u$ '. In a clausal island, any constituent movement is prohibited. Heading an island complement, a high linker is not designated an EPP feature and is thus realized as a weak complementizer that cannot host a DP operator. Utterance verbs, non-factive cognition verbs (e.g., "believe"), and epistemic/evidential modals c-select normal finite complements headed by the mid linkers $n a, m h a, c u_{\mathrm{M}}^{\prime},{ }^{\prime}{ }_{\mathrm{M}}, g a$, and $k i_{\mathrm{M}}$. In a normal finite complement, DP extraction is allowed. A mid linker is thus realized as a strong complementizer and is designated an EPP feature. As an [EPP] complementizer, a mid linker is able to host a nominal operator in its specifier position and does not block extractions. Low-linking constructions are divided into three categories. The deontic modal c-selects a non-finite AspP that is sensitive to extraction patterns and is introduced by the type A low linker $k i_{\mathrm{LA}}^{\prime}$. The linker $k i_{\mathrm{LA}}^{\prime}$ occupies the head position of an AspP and is designated an [EPP] feature. Tough/middle predicates and object control verbs c-select a non-finite $\mathrm{CP}$ introduced

Table 3 Verb/predicate types and the selection of linkers in Mayrinax Atayal (II)

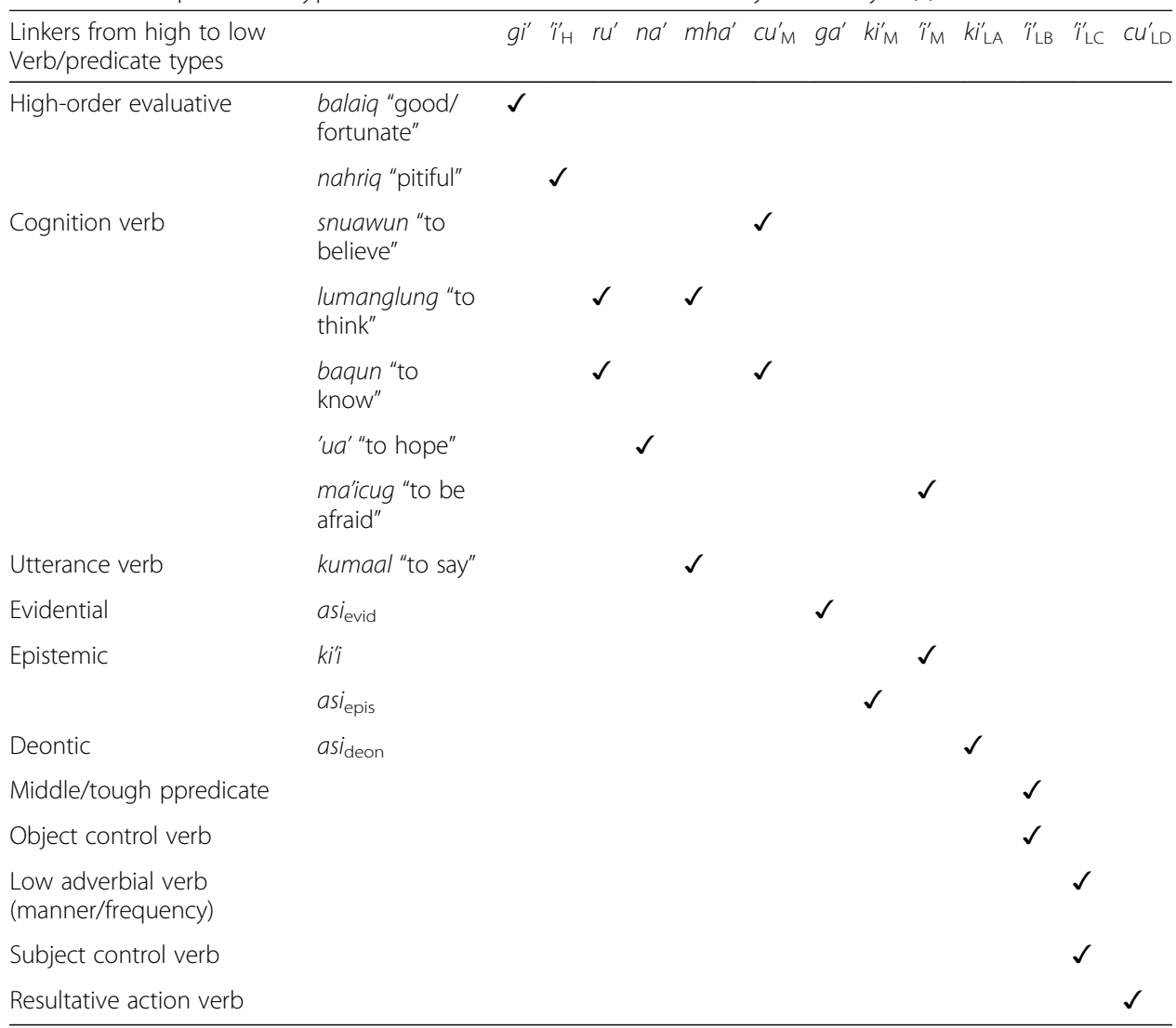




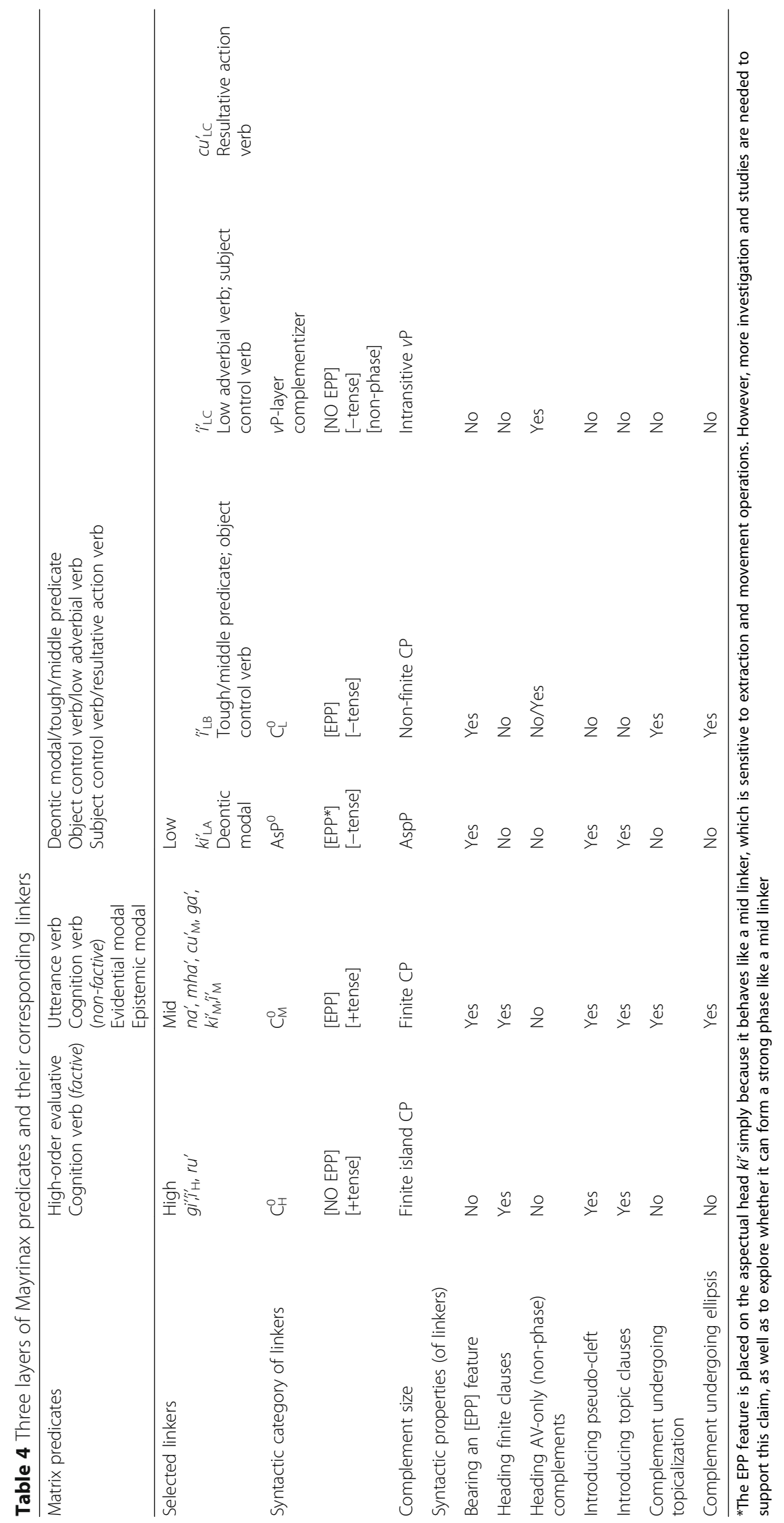


by the type B low linker ' $i$ ' lipsis that target the finite $\mathrm{CP}$ are also sensitive to the non-finite $\mathrm{CP}$ headed by the type B low linker. The type B low linker ' $i$ ' and is designated an [EPP] feature that is able to host a nominal operator in its SPEC position. Low adverbial verbs and subject control verbs c-select an intransitive $v \mathrm{P}$ headed by the type $C$ low linker ' $i$ ', , while active causative verbs select an intransitive $\nu \mathrm{P}$ headed by $c u_{\mathrm{LC}}^{\prime}$. Syntactic operations such as clausal topicalization and ellipsis that target finite and non-finite CPs do not target the intransitive $\nu \mathrm{P}$ introduced by ${ }^{\prime}{ }_{\mathrm{LC}}$, or $c u_{\mathrm{LC}}^{\prime}$. Heading non-phase complements, type $\mathrm{C}$ low linkers are realized as a defective $\nu$ P-layer complementizer without an EPP feature ${ }^{\mathrm{w}}$; they constitute non-phase phrases and are insensitive to the syntactic operations of DP movement.

From a cartographic point of view (cf. Rizzi 1997x; Tsai and Wu 2012), how all sorts of matrix verbs work to shape the "topography" of linking constructions in Mayrinax Atayal is visualized in Fig. 11.

The examples in (83) demonstrate the cartography of homophonous linkers structured from high to low. In (83a), the Mayrinax linkers ' $i_{\mathrm{H}}{ }^{\prime}, i_{\mathrm{M}}$, and ${ }^{\prime} i_{\mathrm{L}}$ appear in both the complementizer layer and the lexical layer, corresponding respectively to the modal usage on the upper tier of the sentence structure and the adverbial usage on the lower tier. It is obvious that $c u_{M}^{\prime}$ and $c u_{\mathrm{L}}^{\prime}$ in (83b) have a similar distribution.

(83)

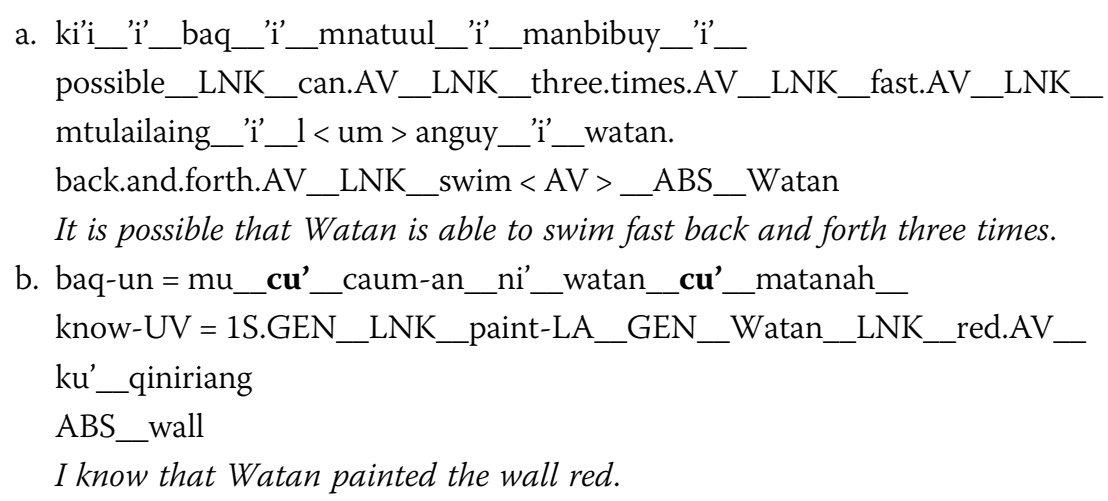

The examples in (84) show different types of linking constructions starting from the upper complementizer layer, where the high linkers $g i$ ' and $r u^{\prime}$ occur, to the lower complementizer layer, where the mid linkers $m h a, c u^{\prime}{ }_{M}, i_{M}^{\prime}$, and $g a^{\prime}$ occur ${ }^{\mathrm{y}}$, and finally to the lexical layer, where the low linkers ${ }^{\prime} i_{\mathrm{L}}^{\prime}$ and $c u_{\mathrm{L}}^{\prime}$ occur.

(84) a. balaiq_gi'_asi_ga'_pa-k-balaiq_'i'_'an-hi-hiyawun

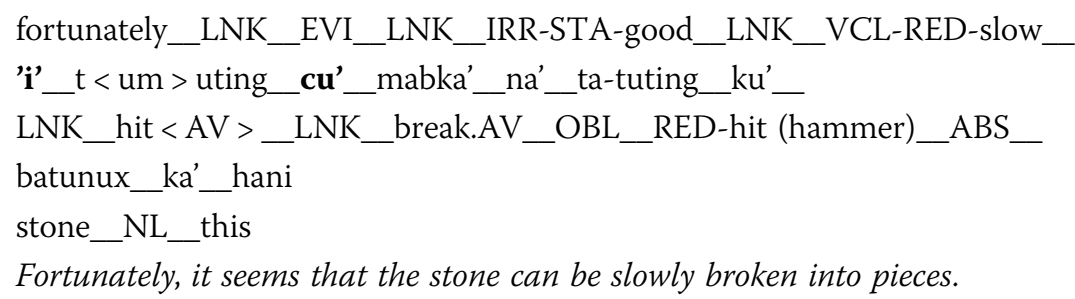




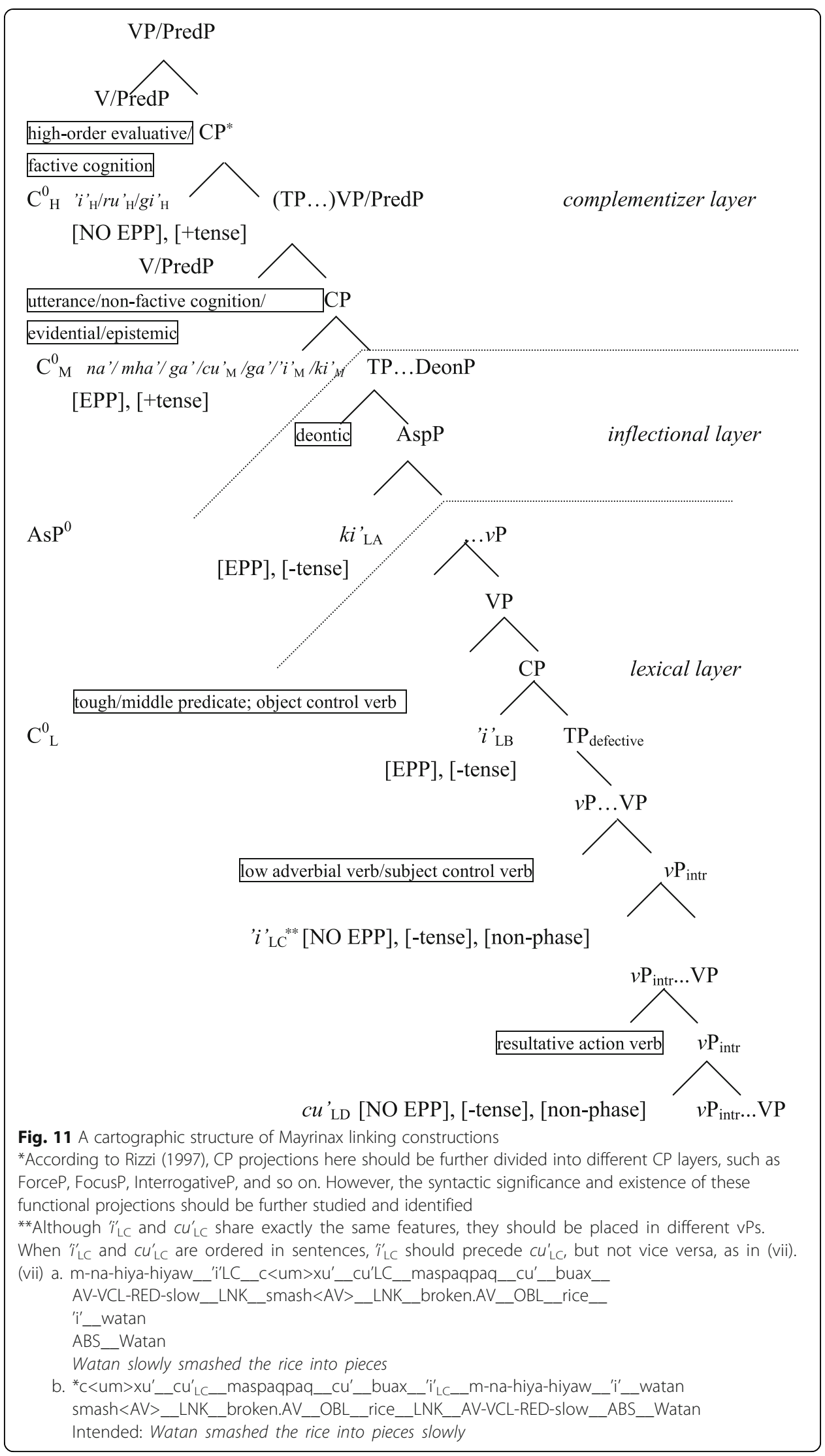




\author{
EVI_LNK_AV-VCL-RED-day (often)_LNK_AV-go__ \\ i'_thaypaq_'i'_p-si-baq_cu'_ruas \\ LOC_Taipei_LNK_CAU-SI-be.able.to.AV_OOBL_book \\ Watan thought afterward that he might go to Taipei to teach often.
}

The linker hierarchy demonstrated in (83a), (83b), (84a), and (84b) is actually a reflection of the predicate hierarchy. The predicate hierarchy reflected in (83a), (83b), (84a), and (84b) is illustrated in (85a), (85b), (85c), and (85d), respectively.

(85) a. [epistemic modal $>$ dynamic modal $>$ frequency $>$ manner $>$ manner $>\mathrm{V}$ ]

b. [cognition verb $>\mathrm{V}>$ resultative verb]

c. $[$ Evaluative predicate $>$ evidential predicate $>$ epistemic/permission modal $>$ manner adverbial verb $>\mathrm{V}>$ resultative verb]

d. [cognition verb $>$ evidential predicate $>$ frequency adverbial verb $>\mathrm{V}>\mathrm{V}$ ]

In spite of minor language-specific differences, these findings, to a large degree, accord with the following predicate/adverbial hierarchy that has been established in and verified by a huge number of languages, as proposed in Cinque (1999).

(86) Universal predicate/adverbial hierarchy (Cinque 1999: 106)

[frankly Mood-speech act [fortunately Mood-evaluative [allegedly Moodevidential [probably Mod-epistemic [once T(Past) [then T(Future) [perhaps Mood-irrealis [necessarily Mod-necessity [possibly Modpossibility [usually Asp-habitual [again Asp-repetitive(I) [often Aspfrequentative (I) [intentionally Mod-volitional [quickly Asp-celerative (I) [already $\mathrm{T}$ (Anterior) [no longer Asp-terminative [still Asp-continuative [always Asp-perfect [just Asp-retrospective [soon Asp-proximative [briefly Asp-durative [characteristically Asp-generic/progressive [almost Asp-prospective [completely Asp-SgCompletive (I) [tutto Asp-PlCompletive [well Voice [fast/early Asp-celerative(II) [again Asp-repetitive (II) [often Asp-frequentative (II) [completely Asp-SgCompletive(II)

Cinque (1999) has argued that there is a systematic one-to-one correspondence between the hierarchies of adverbs and clausal functional heads observed in various languages and proposed that adverbs occur in the specifier position of various functional projections. Rather than being merged into the SPEC position of functional heads, however, Mayrinax realizes adverbials in head positions like many other Formosan languages (Chang 2006).

\title{
5 Conclusions
}

This study has demonstrated and categorized different types of linking constructions utilized in both finite and non-finite environments. It has also categorized different levels of complement-taking predicates and analyzed the syntactic statuses of various selected linkers, with respect to their syntactic function and representation manifested in different layers of hierarchical structures. The study revealed that matrix predicates exert strong selectional restrictions on linkers and 
complements. These selectional restrictions imposed by matrix predicates determine diverse complement structures and provide linkers with their specific syntactic functions and features. Given that such a selectional relationship is obligatory, Mayrinax linkers occupy fixed and selected structural positions. The syntactic features and properties of linkers are not self-prompted but are conditioned and designated by their structure. This selection-based analysis can also explain the sensitivity/insensitivity to various syntactic operations, such as extraction and movement, found with different linking elements.

\section{Endnotes}

${ }^{a}$ Functional verbs refer to auxiliary verbs and adverbial verbs; lexical verbs mainly consist of dynamic verbs and stative verbs.

${ }^{\mathrm{b}}$ Chang (2010) indicated that adverbial verb constructions (AVCs) are heterogeneous and vary from one language to another in their structural representations. One simple indication of this diversity is the absence or presence of linkers in AVCs. Formosan languages such as Paiwan, Mayrinax Atayal, and Amis are linker languages in which adverbial verbs and lexical verbs are connected with a linker. Languages like Kavalan, Puyuma, Squliq Atayal, and Kanakanavu are classified as "linkerless" languages in which verbs are simply juxtaposed without any linking element.

${ }^{\mathrm{c}}$ Abbreviations in this paper are listed as follows:

\begin{tabular}{llll}
\hline 1 & First person & LOC & Locative case \\
2 & Second person & LNK & Linker \\
3 & Third person & NEG & Negative \\
AV & Agent voice & NIND & Non-indicative \\
ABS & Absolutive case & NL & Nominal ligature \\
ACC & Accusative case & NOM & Nominative case \\
CA & Circumstantial & OBL & Oblique case \\
CAU & applicative & PERF & Perfective \\
CONJ & Causative & PL & Plural \\
COS & Conjunction & PROG & Progressive \\
DEON & Change-of-state marker & RED & Reduplication \\
DUR & Ceontic modal & S & Singular \\
EVI & Durative & STA & Stative marker \\
FUT & Evidential modal & SUB & Subordinator \\
GEN & Future & TAM & Tense/aspect/modality \\
IMP & Genitive case & TOP & Topic marker \\
IRR & Imperative & UV & Undergoer voice \\
LA & Irrealis & VCL & Verb classifier \\
AspP & Locative applicative & CP & Complementizer phrase \\
VP & Aspect phrase & EPP & Extended projection \\
TP & Light verb phrase & & principle \\
MP & Minimalist program & Determiner phrase \\
\hline & & \\
\hline
\end{tabular}


${ }^{\mathrm{d}}$ This study confined adverbial verbs to the inner/low adverbial category, which modifies events or actions, that is, manner and frequency adverbials (cf. Chang 2010).

${ }^{\mathrm{e}}$ Cognition verbs may include verbs of mental attitude (e.g., think, know, hope, believe) or verbs of mental state, sensation, and emotion (e.g., fear, feel, regret) (cf. Givón 2001).

${ }^{\mathrm{f}}$ According to $\mathrm{Yu}$ (2015), the Mayrinax asi has two other readings. It may function as an evidential predicate or a deontic modal.

${ }^{\mathrm{g}}$ The reason for using the term "generic" is because the evaluative verb involves a generic mood that expresses general truth based on the speaker's observations or attitudes. A generalized statement is expected to be widely accepted by others. Usually, the generic mood (gnomic) is considered neutral by not limiting a proposition, event, or action to the past, present, or future (Carlson and Pelletier 1995). Morphosyntactically, these evaluatives are bare in form because they do not need to specify the tense/aspect of verb forms involving the generic mood. In addition, the reason for labeling evaluative verbs as stative is because they follow the morphosyntactic alternation specified for stative verbs (Zeitoun and Huang 2000). In negative/causative/imperative constructions, evaluative verbs must occur with the stative marker $k a-$, as in (i).

$$
\begin{array}{lll}
\text { ini' } & \mathbf{k}(\mathbf{a}) \text {-nahriq } & \text { 'i'watan } \\
\text { NEG } & \text { STA-pitiful } & \text { ABS }
\end{array}
$$

Watan Watan is not a poor guy.

h"Aspectual verbs", "motion verbs", and "dynamic modal verbs" were chosen as subject control verbs because these control predicates may select an "originator", an actor or a capable agent, as the subject. These verbs may also stand independently as a short response clause for a question, as in (iia-b), but adverbial verbs (like frequency verbs) cannot, as in (iiia-b). This indicates that to answer a question sentence using linking constructions, the subject control verb solely supports a subject as a short answer, but the adverbial verb cannot.

(ii) a. ima'_ku'_[m-naqru'_i'_matawwaw]

$$
\begin{aligned}
& \text { Who_ABS_AV-begin_LNK__work.AV } \\
& \text { Who began to work? }
\end{aligned}
$$

b. m-naqru'_'i'_watan

AV-begin__ABS_Watan

Intended: Watan began to work.

(iii) a. ima'_ku'_[m-na-ri'a-ri'ax_'i'_c $<u m>$ bu'_cu'_bauwak]

Who_ABS_AV-VCL-RED-day_LNK_shoot_OBL_pig

Who shoots pigs often?

b. "m-na-ri'a-ri'ax_'i'_watan

AV-VCL-RED-day_ABS_Watan

In this sense, the subject control verb is obligatory in subject control constructions because the arguments (PRO) of the embedded verbs are clearly controlled by the matrix subjects/agents.

${ }^{\mathrm{i}}$ Note that the terminology here is based on a thematic definition rather than a syntactic one. According to Huang (1995), Mayrinax does not permit a manipulative verb to be realized in its AV form, as in (iv).

(iv) 's<um $>$ iwal_cku'_ulaqi'_i'_limuy__i'_maniq_cu'_qulih

allow $<\mathrm{AV}>$ _OBL_child_ABS_Limuy_LNK_eat.AV_OOBL_fish

Intended: Limuy allows the child to eat fish. 
The manipulative verb must surface in its NAV form. In this sense, the controller is assigned the nominative case by the manipulative verb. The object control construction is actually in the subject's control. This particular constraint may be attributed to the ergative nature of this language.

${ }^{j}$ The circumstantial si-functions like an applicative marker that promotes oblique arguments (such as beneficiary, instrument, malefactive, transported theme, and cause) to the core position (Chang 2015; Chen 2007).

${ }^{k}$ In spite of several exceptions, the causative-preceding-resultative word order is commonly observed cross-linguistically (Nedjalkov 1988). The word order of the elements in Mayrinax is constant and crucial in conveying the resultative meaning. This strict word order reflects the temporal sequence in which an actual event in a causal chain takes place, as well as implies iconicity-the sequential order of causal events described is mirrored in the linguistic form.

${ }^{\mathrm{I}}$ In the middle/tough construction, the subject is situated in the middle between the AV (in the matrix clause) and the UV (in the embedded clause), which is why the term middle is used here. The subject receives two thematic roles: the theme from the matrix verb and the undergoer (patient/instrument) from the embedded verb. Structurally, in (23c) in the main text, the ABS-marked embedded patient ruas seems to be the shared subject of the matrix clause and the embedded clause but is actually base-generated in the matrix clause (Wu 2013). By contrast, this type of theta-role association is not attested in constructions with an AV-only restriction. Moreover, according to Chang (2010), the subject-marked embedded patient in the NAV adverbial verb construction is base-generated in the embedded clause.

${ }^{\mathrm{m}}$ According to the c-selection principle, matrix verbs determine the syntactic category of their complements. In Mayrinax, middle/tough predicates may subcategorize for a non-finite complement clause without an AV-only restriction. Just like in English, for example, the tough predicate "hard" c-selects an infinitive complement, as in "This book is hard [to read]."

${ }^{\mathrm{n}}$ One possibility can be that if the AV stative verb shifts to an NAV, it will complicate the argument structure. An NAV stative predicate implies that there will be an additional causer and causee. The sentence will be ungrammatical and unintelligible in this case. However, more investigation and tests are needed to explain this special restriction.

${ }^{\circ}$ According to Tsai (1997) and Potsdam (2006), wh-extraction in sentences such as (28b) involve the following pseudo-cleft construal:

(v) $\left[\right.$ predicate nanuan $\left.{ }_{\mathrm{k}}\right]$ _ [subject $\left.\mathrm{ku}^{\prime}\left[[\mathrm{e}]_{\mathrm{k}}\left[\mathrm{Op}_{\mathrm{k}}\left[\ldots . . \mathrm{t}_{\mathrm{k}}\right]\right]\right]\right]$ what_ABS

In other words, the subject in question is a headless relative, and what undergoes extraction is the null relative operator Op, not the wh-expression itself. The null operator is then identified with the empty subject [e] (as marked by $k u^{\prime}$ ). Consequently, nanuan "what" in the sentence-initial position does not occur within the complex subject. Rather, it serves as a predicate nominal in the equational sentence illustrated above.

${ }^{\mathrm{P}}$ Clitic climbing in Mayrinax Atayal should be treated as a type of head movement that brings clitics from their base position successively into their final position (Kayne 1975; Rizzi 1986; Uriagereka 1995), rather than the A'-movement. The blocking effect is feasible for both the $A^{\prime}$-movement and the head movement since extracting any elements from an island is prohibited. 
${ }^{\mathrm{q}}$ The blocking effect also can be attested in the English factive-complement island headed by the complementizer "that", as in (vib-c). Example (vi) demonstrates the factive-island constraint in the English "regret" complement. The factive complements in (vib-c) disallow long-distance DP extractions (Haegeman 2006; Melvold 1991; Rooryck 1992; Varlokosta 1994).

(vi) a. John regretted that Jane married Tom.

b. "Who did John regretted that married Tom?

c. *Whom did John regretted that Jane married?

However, ru', ' $i$,' and $g i$ ' in Mayrinax cannot be totally treated on a par with the English factive-complementizer "that" because they have different historical origins. Further investigation and studies are needed to explain their differences.

${ }^{r}$ In Tsai's (2003) analysis, the argument type wh-sentence involved a pseudo-cleft construction in which the wh-predicate was followed by a nominalized headless relative clause. In (46a) of the main text, the headless relative clause $(\mathrm{CP})$ is marked by the ABS case marker $k u$,' which is the reason why structurally a DP occurs before the CP.

sThe terms "factive" and "non-factive" are used simply to account for the spilt behaviors of cognition verbs in wh-extraction. This distinction indicates that the island/non-island effect attested both in English and Mayrinax does not happen to be a coincidence but is actually a shared property in Universal Grammar. However, the typology of islandhood varies from language to language. For example, English "think," which does not block extraction in "that" clauses, is never a factive verb. However, the behaviors of the Mayrinax "think" verb langlung is rather complicated. Langlung can be either a factive verb (when it patterns with $r u^{\prime}$ clauses) or a non-factive verb (when it patterns with $m h a^{\prime}$ clauses) (Liu 2011). One must also notice that even though these linkers behave somewhat like the English complementizer "that" with regard to wh-extraction, each of these linkers has a distinctive historical origin, which may have an impact on their current behaviors as complementizers. More investigation and studies are needed for this complicated issue.

${ }^{t}$ The Minimal Link Condition, also known as the Shortest Link or Shortest Move, states that derivations with shorter links are preferred over derivations with longer links. In the minimalist program, the MLC accounts for superiority condition effects, wh-islands, and super raising.

'The syntactic status of the optional linker ' $i$ ' (placed after kia) is tricky. Like the linker occurring in tough/middle constructions, it heads a tenseless complement clause that can freely carry voice markers (Wu 2013). Unlike other linkers in discussion that should obligatorily occur, however, the linker ' $i$ ' here can be omitted in sentences. In this study, this optional linker was excluded in the discussion. One of the anonymous reviewers pointed out that a progressive aspect kia may block extraction from a nonfinite complement. One may consider the possibility that it is quite common across languages for an (outer) aspect to develop tense-like behavior through certain syntactic mechanisms (e.g., the past construal of perfective aspects in British English and Taiwan Mandarin). However, further investigation and tests are needed for a better understanding of its syntactic behaviors.

"By definition, langlung "think" in Mayrinax Atayal should be a non-factive verb (Kiparsky and Kiparsky 1971). According to the data, however, langlung "think" may select an island $r u^{\prime}$ complement that blocks extractions, and it may also select a normal mha' complement that does not block extractions. It has been suggested that the cognition 
verb langlung may somehow undergo a semantic shift from non-factive to factive when it patterns with the $r u^{\prime}$ complement. More investigation is necessary for this assumption.

${ }^{\mathrm{w}}$ The absence of an EPP feature indicates two situations: (i) a high $\mathrm{C}$ heading a finite island complement projects a weak phase (a possible exit but it is defective); and (ii) a $v \mathrm{P}$-layer complementizer heads a non-phase phrase (an intransitive $\nu \mathrm{P}$ that is insensitive to extraction operations).

${ }^{\mathrm{x}}$ The reason why I do not follow Rizzi's (1997) proposal here is that this paper focuses on how the linkers are categorized and realized in a hierarchical structure. Although this paper discusses how these linkers interact with wh- and topic constructions, it has not addressed the issue of how the topic phase and the interrogative phase are arranged and organized in the hierarchical structures of linking constructions. In order to solve this puzzle, more investigation and tests are needed.

${ }^{\mathrm{y}}$ Mayrinax predicates/linkers should be further considered regarding their ordering within each individual layer. That is to say, predicates/linkers in each predicate/linker layer have their own relative ordering. For example, the mid-level predicates asi and lumanglung and the mid linkers $g a^{\prime}$ and $m h a^{\prime}$ can be ordered as follows:

(viii) asi_ga'_l<um>anglung_i'_watan__mha'_m<in $>$ usa'_i'_bari_seem_LNK _think $<\mathrm{AV}>$ _ABS_Watan_LNK_go $<\mathrm{PERF}>$ _LOC_Miaoli_'i'_tali'ABS_Tali It seems that Watan thought that Tali went to Miaoli.

Further studies are needed to explore and elaborate the exact predicate/linker ordering within each syntactic layer.

Competing interests

The author declares that he has no competing interests.

Received: 14 May 2016 Accepted: 5 May 2017

Published online: 28 August 2017

References

Aldridge, Edith. 2004. Ergativity and word order in Austronesian languages. Ph.D. dissertation. Ithaca, NY: Cornell University.

Aldridge, Edith. 2008. Phase-based account of extraction in Indonesian. Lingua 118(10): 1440-1469.

Basse, Galen. 2008. Factive complements as defective phases. In Proceedings of the 27th West Coast Conference on Formal Linguistics, ed. Natasha Abner and Jason Bishop, 54-62. Somerville, MA: Cascadilla Press.

Carlson, Gregory N, and Francis J Pelletier (eds.). 1995. The generic book. Chicago, IL: University of Chicago Press.

Chang, Yungli H. 2006. The guest playing host: Modifiers as matrix verbs in Kavalan. In Clause structure and adjuncts in Austronesian languages, ed. Hans-Martin Gärtner, Paul Law, and Joachim Sabel, 43-82. Berlin: Mouton de Gruyter.

Chang, Yungli. 2009. Adverbial verbs and adverbial compounds in Tsou: A syntactic analysis. Oceanic Linguistics 48(2): 439-476

Chang, Yungli H. 2010. On the syntax of adverbial verbs in Formosan languages. In Austronesian contribution to theoretical linguistics, ed. Raphael Mercado, Eric Potsdam, and Lisa deMena Travis, 183-211. Amsterdam/ Philadelphia: John Benjamins.

Chang, Yungli H. 2015. Extractions in Tsou causative applicatives. Lingua Sinica 1(1): 1-48.

Chang, Yungli H, and Wei-tien D Tsai. 2001. Actor-sensitivity and obligatory control in Kavalan and some other Formosan languages. Language and Linguistics 2(1): 1-20.

Chen, Shih-wei. 2007. Applicative constructions in Squliq Atayal. M.A. thesis. Hsinchu, Taiwan: National Tsing Hua University.

Chen, Yi-ting. 2008. A minimalist approach to Amis structure and complementation. Ph.D. dissertation. Tempe, AZ: Arizona State University.

Chen, Yi-ting. 2010. The Amis left periphery. Oceanic Linguistics 49(2): 339-358.

Chen, Tingchun. 2012. Restructuring in Mayrinax Atayal. Paper presented at the 19th Austronesian Formal Linguistics Association Annual Conference. Taipei.

Chomsky, Noam. 1995. The minimalist program. Cambridge, MA: MIT Press.

Chomsky, Noam. 2001. Derivation by phase. In Ken Hale: A life in language, ed. Michael Kenstowicz, 1-52. Cambridge, MA: MIT Press.

Chomsky, Noam. 2007. Approaching UG from below. In Interfaces + Recursion = Language?, ed. Uli Sauerland and Hans-Martin Gärtner, 1-30. Berlin: Mouton de Gruyter.

Cinque, Guglielmo. 1999. Adverbs and functional heads: A cross-linguistic perspective. New York: Oxford University Press.

Dai, Chiahao, Chaili Bei, and Chunming Wu. 2010. On modals in Mayrinax Atayal. Paper presented at the 17th Austronesian Formal Linguistics Association Annual Conference, Stony Brook, New York. 
Givón, Talmy. 2001. Syntax: An introduction, vol. 1-2. Amsterdam/Philadelphia: John Benjamins.

Haegeman, Liliane. 2006. Conditionals, factives and the left periphery. Lingua 116(10): 1651-1669.

Huang, James C-T. 1982. Logical relations in Chinese and the theory of grammar. Ph.D. dissertation. Cambridge, MA: MIT.

Huang, Mei-jin L. 1995. A study of Mayrinax syntax. Taipei: Crane.

Huang, Mei-jin L. 1997. Serial verb construction in some Formosan Languages: A typological review. Paper presented at the 8th International Conference on Austronesian Linguistics, Taipei.

Kayne, Richard S. 1975. French syntax: The transformational cycle. Cambridge, MA: MIT Press.

Kiparsky, Paul, and Carol Kiparsky. 1971. Fact. In Semantics: An interdisciplinary reader in Philosophy, Lingusitics and Psychology, ed. Danny D Steinberg and Leon A Jakobovits, 345-369. New York: Cambridge University Press.

Koster, Jan, and Robert May. 1982. On the constituency of infinitives. Language 58(1): 116-143.

Liu, Tsai-hsiu. 2011. Complementation in three Formosan languages—Amis, Mayrinax Atayal and Tsou. Ph.D. dissertation. Manoa, HI: University of Hawaii.

Melvold, Janis. 1991. Factivity and definiteness. In MIT working papers in linguistics, vol. 15: More papers on wh-movement, ed. Lisa L-S Cheng and Hamida Demirdache, 97-117. Cambridge, MA: MITWPL.

Metcalf, Vanessa. 2005. Argument structure in HPSG as a lexical property: Evidence from English purpose infinitives. In OSU working papers in Linguistics: Locality of grammatical relationships no. 58, ed. Robert D Levine and Walt D Meurers, 1-28. Columbus, OH: Department of Linguistics at Ohio State University.

Nedjalkov, Vladimir. 1988. Typology of resultative constructions. In English translation, ed. Bernard Comrie. Amsterdam: John Benjamins.

Potsdam, Eric. 2006. More concealed pseudoclefts in Malagasy and the clausal typing hypothesis. Lingua 116(12): 2154-2182.

Rackowski, Andrea. 2002. The structure of Tagalog: Specificity, voice, and the distribution of arguments. Ph.D. dissertation. Cambridge, MA: MIT

Rackowski, Andrea, and Norvin Richards. 2005. Phrase edge and extraction: A Tagalog case study. Linguistic Inquiry 36(4): 565-599.

Rizzi, Luigi. 1986. On chain formation. In The syntax of pronominal clitics: Syntax and semantics, vol. 19, ed. Hagit Borer, 65-95. New York: Academic Press.

Rizzi, Luigi. 1997. The fine structure of the left periphery. In Elements of grammar, ed. Liliane Haegeman, 281-337. Dordrecht, The Netherlands: Kluwer Academic Publishers.

Rooryck, Johan. 1992. Negative and factive islands revisited. Journal of Linguistics 28(2): 343-374.

Tang, Chih-Chen J. 1999. On clausal complements in Paiwan. Selected papers from the 8th ICAL, 529-578. Taipei.

Tsai, Wei-Tien D. 1997. Indefinite wh-construals in Formosan languages: A comparative study of Kavalan, Tsou, and Seediq. Tsing Hua Journal of Chinese Studies (New Series) 27(4): 381-422.

Tsai, Wei-Tien D. 2003. Lexical courtesy revisited: Evidence from Tsou and Seediq wh-constructions. Gengo Kenkyu Journal of the Linguistic Society of Japan 123: 331-361.

Tsai, Wei-Tien D, and Chunming Wu. 2012. Conjunctive reduction revisited: Evidence from Mayrinax Atayal and Southern Paiwan. Oceanic Linguistics 51(1): 160-181.

Uriagereka, Juan. 1995. Aspects of the syntax of clitic placement in Western Romance. Linguistic Inquiry 26(1): 79-123.

Varlokosta, Spyridoula. 1994. Factivity, factive complements and wh-extraction. Proceedings of the 6th Annual Student Conference in Linguistics. In MIT working papers in linguistics, vol. 23: Proceedings of the 6th Annual Student Conference in Linguistics, ed. Chris Giordano and Daniel Ardron, 317-336. Cambridge, MA: MITWPL.

Wu, Chunming. 2013. The syntax of linking constructions in Mayrinax Atayal and Sinvaudjan Paiwan. Ph.D. dissertation. Hsinchu, Taiwan: National Tsinghua University.

Yu, Xin-xian. 2015. Modals and mood particles in Mandarin Chinese and Mayrinax Atayal. Ph.D. dissertation. Hsinchu, Taiwan: National Tsing Hua University.

Zeitoun, Elizabeth, and Mei-jin L Huang. 2000. Concerning ka-, an overlooked marker of verbal derivation in Formosan languages. Oceanic Linguistics 39(2): 391-414.

Submit your manuscript to a SpringerOpen ${ }^{\circ}$ journal and benefit from:

- Convenient online submission

- Rigorous peer review

- Open access: articles freely available online

- High visibility within the field

Retaining the copyright to your article

Submit your next manuscript at springeropen.com 